This item was submitted to Loughborough's Research Repository by the author.

Items in Figshare are protected by copyright, with all rights reserved, unless otherwise indicated.

\title{
Optimization of life-cycle maintenance of deteriorating bridges with respect to expected annual system failure rate and expected cumulative cost
}

\section{PLEASE CITE THE PUBLISHED VERSION}

http://dx.doi.org/10.1061/(ASCE)ST.1943-541X.0000812

\section{PUBLISHER}

(C) American Society of Civil Engineers (ASCE)

\section{VERSION}

AM (Accepted Manuscript)

\section{PUBLISHER STATEMENT}

This work is made available according to the conditions of the Creative Commons Attribution-NonCommercialNoDerivatives 4.0 International (CC BY-NC-ND 4.0) licence. Full details of this licence are available at: https://creativecommons.org/licenses/by-nc-nd/4.0/

\section{LICENCE}

CC BY-NC-ND 4.0

\section{REPOSITORY RECORD}

Barone, Giorgio, Dan M. Frangopol, and Mohamed Soliman. 2019. "Optimization of Life-cycle Maintenance of Deteriorating Bridges with Respect to Expected Annual System Failure Rate and Expected Cumulative Cost". figshare. https://hdl.handle.net/2134/16760. 


\title{
Optimization of life-cycle maintenance of deteriorating bridges \\ considering expected annual system failure rate and expected \\ cumulative cost
} Giorgio Barone ${ }^{1}$, Dan M. Frangopol, Dist. M.ASCE ${ }^{2 *}$ and Mohamed Soliman,
S.M.ASCE

\begin{abstract}
Civil infrastructure systems are subjected to progressive deterioration resulting from multiple mechanical and environmental stressors. This deterioration process is developed under uncertainties related to load effects, structural resistance, and inspection outcomes, among others. In this context, life-cycle optimization techniques provide a rational approach to manage these systems considering uncertainties as well as several budgetary and safety constraints. This paper proposes a novel optimization procedure for life-cycle inspection and maintenance planning of aging structures. In this procedure, the structural system effects are accounted for by modeling the structure as a series, parallel, or a series-parallel system whose components are subjected to time-dependent deterioration phenomena. Different possible repair options are considered depending on the damage state and the outcomes of each inspection. For each component, essential or preventive maintenance aiming at reducing the system failure rate, are performed when inspection results indicate that the prescribed threshold damage levels have been reached or violated. Otherwise, no repair is performed. Optimum inspection and maintenance plans are formulated by minimizing both the expected system failure rate and expected cumulative inspection and maintenance cost over the lifecycle of the structure. The proposed approach is applied to an existing bridge.
\end{abstract}

ASCE Subject Headings: optimization; deterioration; inspection; maintenance.

Author keywords: optimization; life-cycle management; inspection and maintenance planning; deteriorating structures; failure rate; uncertainties.

\footnotetext{
${ }^{1}$ Research Associate, Department of Civil and Environmental Engineering, Engineering Research Center for Advanced Technology for Large Structural Systems (ATLSS Center), Lehigh University, 117 ATLSS Dr., Bethlehem, PA 18015-4729, USA, gib212@lehigh.edu.

${ }^{2}$ Professor and the Fazlur R. Khan Endowed Chair of Structural Engineering and Architecture, Department of Civil and Environmental Engineering, Engineering Research Center for Advanced Technology for Large Structural Systems (ATLSS Center), Lehigh University, 117 ATLSS Dr., Bethlehem, PA 18015-4729, USA, dan.frangopol@lehigh.edu, *Corresponding Author.

${ }^{3}$ Graduate Research Assistant, Ph.D. Candidate, Department of Civil and Environmental Engineering, Engineering Research Center for Advanced Technology for Large Structural Systems (ATLSS Center), Lehigh University, 117 ATLSS Dr., Bethlehem, PA 18015-4729, USA, mos209@lehigh.edu.
} 


\section{Introduction}

Civil infrastructure systems are continuously subjected to aging phenomena. The separate or combined effects of resistance reduction and/or increase of loads over time lead to a reduction of structural safety. Cost-effective maintenance strategies are needed to guarantee adequate structural reliability levels with respect to different limit states. Decision-making processes for the development of optimal maintenance plans have to consider all epistemic and aleatory uncertainties that may affect the structure during its life-cycle. Life-cycle probabilistic concepts and methods for the determination of lifetime maintenance plans of deteriorating structures have been largely discussed in recent years and several approaches have been proposed. These concepts and methods are able to establish well-balanced intervention schedules that consider various economic and safety requirements while taking into account uncertainties associated with the time-dependent structural performance. An extensive review of such methods is reported in both Frangopol and Liu (2007) and Frangopol (2011). The main approaches are based on (a) probabilistic performance indicators, (b) risk assessment, or (c) lifetime distribution functions.

With regard to probabilistic performance indicators, the reliability index is recognized to be highly effective for maintenance planning of deteriorating structures. This has been discussed in several papers using decision-tree analysis [Estes and Frangopol 2003], single objective optimization [Mori and Ellingwood 1994], or multi-objective optimization [Orcesi and Frangopol 2011(a)]. While the reliability index is related to the annual probability of failure of the structure, a different indicator can be used considering also economic losses due to failure by using risk-based maintenance planning. Risk-based decision making takes into account both the direct losses associated with failure (e.g. repair or rebuilding costs) [Ramirez et al.2012] and the indirect losses caused by the nonoperational state of the system [Ang and Tang 1984]. Components subjected to higher risk should have top priority for maintenance interventions. Arunraj and Maiti (2007) classify risk-based maintenance techniques based on quantitative or qualitative nature of the risk assessment, type of applications, and input and output data types. 
Although the reliability index and risk, defined in general as a function of the annual failure probability, are associated with a specific point-in-time, lifetime distributions keep memory of the events on the system during the structural life-cycle. Optimal maintenance planning using lifetime distribution functions has been proposed considering single and multi-objective optimization based on system survivor function [Orcesi and Frangopol 2011(b), Okasha and Frangopol 2010]. Failure rate has been considered for preventive maintenance planning of series systems [Caldeira Duarte et al. 2006] and inspection/preventive maintenance schedules have been proposed for a gantry crane using a coupled Bayesian network [Baek et al. 2009]. Failure rate gives the probability of structural failure within a prescribed time interval conditioned on the structural survival up to this time interval. Additionally, it gives an indication on the rate of decrease in the structural reliability, an attribute that makes it a valuable indicator in forecasting the structural performance for life-cycle planning purposes. Recently, Barone and Frangopol (2013) proposed a component-based procedure for determining optimal lifetime inspection/repair plans for deteriorating structures based on the definition of thresholds for the hazard function and using one type of repair (i.e. replacing the damaged component). Their procedure considered a single objective optimization with the goal of minimizing the lifetime hazard function where the output is the optimum number of inspections and their optimal application times.

In this paper, a multi-objective optimal inspection and maintenance planning approach for structural systems subjected to aging phenomena, focusing on the annual failure rate and life-cycle maintenance cost, is proposed. The approach is system-based, in which the interaction of components in the system is considered by modeling the structural configuration as series, parallel, or series-parallel. Two different types of repair are considered in which the selection of the appropriate repair action is based on inspection outcomes and predefined damage level thresholds. For each structural component, when the damage level exceeds a certain threshold, essential maintenance is performed, in which total restoration of the initial component performance is achieved. For minor deterioration levels, preventive maintenance is considered, aiming at arresting the progress of the deteriorating 
phenomena acting on the structure for a period of time. Finally, when the inspection results report negligible damage levels, no repair is performed. Accuracy of inspection is taken into account as a function of the imperfections affecting inspection results. A bi-objective optimization is proposed to minimize both the maximum expected system failure rate over the life-cycle of the system and the expected total cost of all inspection and maintenance actions. Optimal solutions are determined for a given total number of inspections/repairs and inspection accuracy. The proposed approach is applied to an existing bridge considering the effects of deterioration due to corrosion of the girders and of the reinforcement bars of the concrete deck.

\section{Inspection and maintenance options}

Maintenance planning is subjected to several uncertainties related to structural deteriorating phenomena, loadings, quality of inspection procedures, and decisions regarding maintenance types and their costs, among others. Damage assessment through inspections dictates the choice between repairing the structure or not, and eventually what degree of maintenance should be performed. Advanced degradation of the structural performance requires costly repairs aimed to considerably improve the structural reliability, while preventive maintenance may be applied if the structure has still an acceptable service level, reducing the failure rate of the structure with low-cost interventions. Moreover, when the degradation effects are marginal it may be decided not to perform any maintenance actions.

Several inspection techniques exist for assessment and performance prediction of bridges. Visual inspections and non-destructive testing are the most common ones. Visual inspections are primarily performed to estimate structural performance using condition indexes for management decisions. Non-destructive techniques can provide excellent results but, due to their cost, they are usually scheduled at specific times for a particular concern [Frangopol 2011]. Decision on which inspection technique should be applied is dependent on the structure, the desired accuracy, and the cost that can be afforded. Well-timed inspections followed by correct repair decisions may effectively lead to consistent extensions of the lifetime of structures. 
In general, visual inspections take place at regular time intervals. Herein, detailed indepth inspections are considered. Non-destructive techniques are used to obtain detailed data about the structural deterioration state of bridge components. Several techniques (e.g. halfcell potential tests, infrared thermography, ground penetrating radar, among others) have been developed in recent years, each one having its own advantages, costs and applicability [Carino 1999, Clark et al. 2003, Wang et al. 2011].

In this paper, the effect of the degradation is modeled as a continuous reduction of the structural capacity (resistance) $R_{i}(t)$ of the components over time. A rational way to quantify structural capacity over time is to use a probabilistic approach that takes into account imperfections related to the predictive model arising from uncertainties associated with material and structural properties and with the deterioration phenomena that affect the structure. In-depth inspections are able to identify the damage level and, therefore, provide an estimation of the residual capacity of the components at the inspection time. On the other hand, inspection results are affected by imperfections in which the measurement error can be considered to follow a normal distribution with zero mean. Taking into account both the imperfections associated with the structural resistance prediction and the inspection result, the estimated capacity $R_{i}^{(\text {est })}$ for the component $i$ immediately after inspection time $t_{\text {insp }}$ is a random variable having the mean of the predicted structural capacity at that time $\mu_{R_{i}}\left(t_{\text {insp }}\right)$ and standard deviation $\sigma_{\text {insp }}=k_{\text {insp }} \sigma_{R_{i}}\left(t_{\text {insp }}\right)$, where $\sigma_{R_{i}}$ is the standard deviation of the resistance accounting for the imperfections associated with the predictive model and $k_{\text {insp }} \geq 1$ is an index of the inspection accuracy with $k_{\text {insp }}=1$ if no inspection imperfections are considered (i.e., perfect inspection). Sensitivity of solutions to quality of different inspection techniques was reported in Kim et al. (2013).

Three possible repair options are considered for each component, based on the indepth inspection result $R_{i}^{(e s t)}$. In particular, two different thresholds for essential and preventive maintenance, namely $\delta_{E M, i}$ and $\delta_{P M, i}$, where $\delta_{E M, i}<\delta_{P M . i}$, are given for each component to determine the appropriate repair option based on its initial capacity. Essential maintenance, herein defined as total restoration of the component performance to its original value, is performed when $R_{i}^{(e s t)} \leq \delta_{E M, i}$. Preventive maintenance is, instead, applied if the 
estimated component capacity is between the two thresholds, i.e. $\delta_{E M, i}<R_{i}^{(e s t)} \leq \delta_{P M, i}$. It is considered that the effect of the preventive maintenance is to block the effects of the aging phenomena for a certain period, that is the residual capacity remains constant for a given interval of time. The effects of preventive and essential maintenances on the residual capacity are qualitatively represented in Figures 1(a) and 1(b), respectively. Finally, no repair is considered if $R_{i}^{(e s t)}>\delta_{P M, i}$. Therefore, for each component $i$, the probability of essential maintenance $P_{E M, i}$, preventive maintenance $P_{P M, i}$, or no repair $P_{N R, i}$ after one inspection at a given instant of time can be evaluated by integration of the probability density function (PDF) of the estimated residual capacity $f_{R, i}(x, t)$, as:

$$
\begin{aligned}
& P_{E M, i}(t)=\int_{0}^{\delta_{E M, i}} f_{R, i}(x, t) d x \\
& P_{P M, i}(t)=\int_{R_{E M, i}}^{\delta_{P M, i}} f_{R, i}(x, t) d x \\
& P_{N R, i}(t)=1-\left(P_{E M, i}(t)+P_{P M, i}(t)\right)
\end{aligned}
$$

These probabilities are graphically represented as the areas shown in Figure 1(c).

When sequences of inspection/repair are considered, the set of possible events that may occur can be represented by an event tree model in which each branch is associated with a sequence of essential or preventive maintenance, or inspections with no repair. Each branch has a probability of occurrence $P\left(\mathrm{~B}_{k}\right)$, where $k$ is the branch number. Since the tree represents the set of all possible events, obviously $\sum_{k=1}^{N_{b}} P\left(\mathrm{~B}_{k}\right)=1$, where $N_{b}$ is the total number of branches. Figure 2 shows the event tree associated with a single component subjected to two inspections. Possible repair options following each inspection are shown together with the probability associated with each branch. In general, given a system with $N_{C}$ components and $N_{O}$ possible repair options for each component, the total number of different branches after $N_{\text {insp }}$ inspection is given by $N_{b}=\left(N_{O}\right)^{N_{\text {inss }} N_{C}}$. 


\section{Expected annual failure rate and expected total maintenance cost}

For the determination of optimal inspection and maintenance times, several approaches can be used, based on various performance indicators, including reliability index, risk, or lifetime functions. In this paper, attention has been focused on the average system failure rate $h_{s y s}(t)$, defined as the probability of failure occurring between $t$ and $t+\Delta t$, given that the system survives at the time instant $t$, and averaged over the interval $[t, t+\Delta t]$ [Leemis 1995]:

$$
h_{\text {sys }}(t)=\frac{P\left[t \leq T_{F} \leq t+\Delta t \mid T_{F} \geq t\right]}{\Delta t}
$$

The average system failure rate may be rewritten in terms of system survivor function $S_{s y s}(t)$ representing the probability of the system being functional at any time $t$ :

$$
S_{\text {sys }}(t)=P\left[T_{F} \geq t\right]
$$

in which $T_{F}$ is the time of failure occurrence. Therefore, the average system failure rate is:

$$
h_{\text {sys }}(t)=\frac{S_{\text {sys }}(t)-S_{\text {sys }}(t+\Delta t)}{S_{\text {sys }}(t) \Delta t}
$$

The use of this function allows taking advantage of the conditional failure time probability, giving additional information with respect to other performance indicators, such as the pointin-time reliability index. As $\Delta t \rightarrow 0$, Eq. (4) becomes the instantaneous failure rate, which is by definition the hazard function.

For the applications examined in this paper, the annual system failure rate has been considered. First the point-in-time annual probability of failure has been evaluated by using the software RELSYS (RELiability of SYStems) [Estes and Frangopol 1998]. The point-intime probability of system failure is the probability of violating any of the limit state functions that define its failure modes. The limit state function is defined as: 


$$
g(t)=R(t)-Q(t)=0
$$

where $R(t)$ and $Q(t)$ are the resistance and load effect at $t$, respectively. Based on this limit state, the point-in-time probability of failure can be evaluated as:

$$
P_{\text {sys }}(t)=P[\operatorname{any} g(t)<0]
$$

For a series-parallel system, RELSYS first computes the failure probability of all its components. Then, the system is progressively reduced to simpler equivalent subsystems (i.e., having the same reliability of the initial system), until a single equivalent component remains. Once the point-in-time annual failure probability $P_{s y s}(t)$ for the system is known, the time-dependent failure probability at the year $t_{n}$ can be evaluated as [Decò and Frangopol 2011]:

$$
\operatorname{TDP}_{\text {sys }}\left(t_{n}\right)=\sum_{i=1}^{n} P_{s y s}\left(t_{i}\right) \prod_{j=1}^{i-1}\left(1-P_{s y s}\left(t_{j-1}\right)\right)
$$

where $T D P_{\text {sys }}$ represents the cumulative distribution function of the system time-to-failure. Hence, by definition, the system survivor function is:

$$
S_{s y s}(t)=1-T D P_{s y s}(t)
$$

Finally, by considering Eqs. (4) and (8), the annual system failure rate at the year $t_{n}$ is:

$$
h_{\text {sys }}\left(t_{n}\right)=\frac{T D P_{s y s}\left(t_{n+1}\right)-T D P_{s y s}\left(t_{n}\right)}{1-T D P_{s y s}\left(t_{n}\right)}
$$

To determine the optimal set of maintenance times for structural systems, taking into account different maintenance options based on in-depth inspection results, it is necessary to keep track of all possible actions and their occurrence probabilities. Obviously, preventive and essential maintenance provide a reduction of the annual system failure rate. The 
magnitude of this reduction depends on the repair times, deterioration rate of the structural capacity, and loading conditions.

For example, considering a single component subjected to an increasing axial force and a cross-sectional area reduction over time, the structural failure probability can be assessed using the following performance function:

$$
g(t)=A(t) f_{y}-L(t)
$$

where $A(t)$ and $L(t)$ represent the time-variant cross-sectional area and axial load, respectively, and $f_{y}$ is the yield strength of the component material. For illustrative purposes, a deterministic deterioration model, consisting in a continuous loss of cross-sectional area over time, is here considered [Okasha and Frangopol 2009]. The cross-sectional area $A(t)$ is assumed to be a random variable with mean $\mu_{A}(t)$ and standard deviation $\sigma_{A}(t)$ given by:

$$
\begin{aligned}
& \mu_{A}(t)=(1-D R)^{t} A(0) \\
& \sigma_{A}(t)=0.03(1+D R)^{t} A(0)
\end{aligned}
$$

where $A(0)$ is the initial cross-sectional area and $D R$ is the deterioration rate. The load $L(t)$ is modeled as a random variable with mean:

$$
\mu_{L}(t)=(1+l)^{t} L(0)
$$

and coefficient of variation (COV) of $5 \%$, where $L(0)$ is the initial load and $l$ is the load increase parameter. The annual failure rates resulting from performing two inspections after 15 and 25 years of service are presented in Figure 3(a) for three possible branches of the associated event tree (Figure 2). The initial cross-sectional area $A(0)$ and the annual deterioration rate $D R$ are considered to be $3.0 \mathrm{~cm}^{2}$ and $2 \times 10^{-3}$, respectively, whereas initial load and its annual increase rate are assumed $60 \mathrm{kN}$ and $2 \times 10^{-4}$, respectively. The yield stress 
follows a lognormal distribution with parameters shown in Table 1 , and $A(t)$ and $L(t)$ are assumed Gaussian.

The annual failure rate profiles in Figure 3(a) show the effect of essential maintenance (restoring the structural resistance to the initial value) and preventive maintenance (precluding the further degradation in the structural resistance for an effective period of 5 years). As shown, the annual failure rate varies considerably among the different branches after the first inspection. With the aim of representing the effect of the maintenance plan, in an efficient way, by means of a single function that takes into account all the possible events (i.e. preventive or essential maintenance or no repair at each inspection time), the expected annual failure rate, obtained as the summation of the annual failure rates associated with each branch and weighted by their occurrence probabilities $P\left(\mathrm{~B}_{k}\right)$, is:

$$
E\left[h_{s y s}(t)\right]=\sum_{k=1}^{N_{b}} P\left(\mathrm{~B}_{k}\right) h_{s y s, k}(t)
$$

where $N_{b}$ is the total number of branches and $h_{s y s, k}(t)$ is the annual failure rate associated with branch $k$.

When dealing with inspection and maintenance planning optimization, monitoring of cumulative costs over time is crucial. Analogously to the expected annual failure rate, it is convenient to consider the expected total cost of the maintenance plan, obtained as:

$$
E\left[C_{t o t}\right]=\sum_{k=1}^{N_{b}} P\left(B_{k}\right) C_{k}
$$

$C_{k}$ is the total cost of branch $k$, obtained by summing inspection cost, as well as preventive and essential maintenance costs for the considered branch: 


$$
C_{k}=\sum_{i=1}^{N_{\text {insp }}} \frac{C^{(i n s p)}}{\left(1+r_{d}\right)^{t_{\text {insp }}^{(i)}}}+\sum_{j=1}^{N_{P M}} \frac{C_{j}^{(P M)}}{\left(1+r_{d}\right)^{t_{P M}^{(j)}}}+\sum_{j=1}^{N_{E M}} \frac{C_{j}^{(E M)}}{\left(1+r_{d}\right)^{t_{E M}^{(j)}}}
$$

where $C^{(i n s p)}$ is the inspection cost, $C_{j}^{(P M)}$ and $C_{j}^{(E M)}$ are the costs of the $j$-th preventive and essential maintenance actions, respectively, $t_{\text {insp }}^{(i)}$ is the $i$-th inspection time, $t_{P M}^{(j)}$ and $t_{E M}^{(j)}$ are the $j$-th preventive and essential maintenance times, respectively, and $r_{d}$ is the annual discount rate of money, introduced to convert the future monetary value of inspections and repairs, performed at different times, to the present one. In the following, it has been assumed that $r_{d}=0$.

Probabilities of occurrence of the branches $P\left(B_{k}\right)$ for the single component, used to evaluate the expected annual failure rate and expected total cost, are next calculated considering the estimate residual cross-sectional area of the component $A^{(\text {est })}$ resulting from the in-depth inspection outcomes. Two thresholds $\delta_{E M}$ and $\delta_{P M}$ are defined with respect to the initial cross-sectional area of the component to determine the appropriate maintenance type. In particular, for the single component example, three different threshold sets have been considered as follows:

threshold T1: $\delta_{E M, T 1}=0.95 A(0) ; \delta_{P M}=0.98 A(0)$

threshold T2: $\delta_{E M, T 2}=0.90 A(0) ; \delta_{P M}=0.98 A(0)$

threshold T3: $\delta_{E M, T 3}=0.85 A(0) ; \delta_{P M}=0.98 A(0)$

Constraints for performing essential or preventive maintenance are $A^{(e s t)} \leq \delta_{E M, T_{i}}$ and $\delta_{E M, T_{i}}<A^{(e s t)} \leq \delta_{P M}$, respectively. Otherwise, no repair is considered. Therefore, for the threshold set $\mathrm{T} 1$, if the inspection reveals that the residual area is less than $0.95 A(0)$, essential maintenance has to be performed. Additionally, if the residual area obtained by inspection results is between $0.95 A(0)$ and $0.98 A(0)$, preventive maintenance is performed. 
Finally, if the residual area is more than $0.98 A(0)$ no repair is performed after the inspection.

Figure 3(b) illustrates expected annual failure rates for the three threshold sets T1, T2 and T3, assuming inspections to be performed at 15 and 25 years. By increasing $\delta_{E M}$, the probability of performing essential or preventive maintenance is increased or reduced, respectively. Therefore, between the three considered scenarios, T1 is characterized by the lowest expected annual failure rate and the highest expected total cost.

\section{Bi-objective optimization for determining the optimal life-cycle maintenance plan}

A bi-objective optimization procedure is herein proposed to determine the optimal maintenance plan of a multi-component structural system using the lifetime maximum expected system failure rate and the expected total cost as objective functions. To define the optimization problem, an observation time window $t_{\text {tot }}$, as well as the total number of inspections $N_{\text {insp }}$ in the lifetime plan, have to be prescribed. The performance functions

$g_{i}(t)$ for the system components and the in-depth inspection and repair costs have to be defined. Finally, for the proposed model, results will be dependent on the in-depth inspection accuracy.

Based on these assumptions, the Pareto-optimal solution front [Deb 2001] of maintenance plans can be obtained as the solution of the following optimization problem:

Given: $t_{\text {tot }}, N_{\text {insp }}, g_{i}(t), C^{(i n s p)}, C_{i}^{(P M)}, C_{i}^{(E M)}, k_{\text {insp }}$

Find: $\mathbf{t}_{\text {insp }}=\left\{t_{\text {insp }}^{(1)}, \ldots, t_{\text {insp }}^{\left(N_{\text {ins }}\right)}\right\}$

To minimize: $\left\{\begin{array}{l}h_{\max }=\max \left(E\left[h_{\text {sys }}(t)\right]\right) \quad 0 \leq t \leq t_{\text {tot }} \\ E\left[C_{\text {tot }}\right]\end{array}\right.$ 
Such that: $t_{\text {insp }}^{(k+1)}-t_{\text {insp }}^{(k)} \geq \Delta T_{P M} \quad k=1, \ldots, N_{\text {insp }}$

where $C^{(i n s p)}, C_{i}^{(P M)}$ and $C_{i}^{(E M)}$ are the inspection, preventive and essential maintenance costs, respectively, and $k_{\text {insp }}$ is the constant associated with the inspection accuracy previously introduced. The constraints in Eq. (19) have been added to guarantee that, on average, a new preventive maintenance is not performed before the effect of the previous one has ended.

Three different configurations of three-component systems, shown in Figure 4(a), have been studied. The system models cover the series, series-parallel, and parallel configurations. For the $i$-th component of each system, the performance function has been defined, analogously to the single-component example, through Eqs. (10) - (12), taking into account the cross-sectional area loss of the components and the increase of loads over time. Values for the initial cross-sectional areas $A_{i}(0)$, deterioration rates $D R_{i}$, initial load $L(0)$ and coefficient $l$, as well as mean and COV of the components yield stresses $f_{y, i}$ are reported in Table 1. Cross-sectional areas of the components are considered uncorrelated, while perfect correlation is assumed between their yield stresses.

For the three systems, presented in Figures 4(a), annual probabilities of failure for components and systems obtained by RELSYS are plotted in Figure 4(b). As expected, the parallel system yields the lowest annual probability of failure among the three systems. Additionally, for the series-parallel system, the system performance is highly dependent on the behavior of the third component. Figures 5(a), (b), and (c) depict the annual system failure rate of the three structural system models considering an in-depth inspection performed at 20 years of service. Each profile has 27 different repair options after the first inspection, namely no repair, preventive maintenance, and essential maintenance for each of the three components. As shown in Figure 5(b) for the series-parallel system, among the 27 possible branches, it is possible to distinguish three groups related to the maintenance options (i.e., no repair, preventive, essential maintenance) of the critical component (i.e., component 3), whereas for the series or parallel systems, it is not easy to identify these distinctive groups. Therefore, when considering the series-parallel system, although the number of 
branches increases exponentially with the number of components, it is possible to reduce the number of analyzed scenarios focusing the attention exclusively on the most critical components.

Figures 6 (a), (b) and (c) show the expected system failure rate, obtained by Eq. (13), for the series, series-parallel, and parallel systems, respectively. The profiles are associated with the predefined threshold sets T1, T2, and T3 for determining the maintenance type at each inspection.

The bi-objective optimization problem defined by Eqs. (16)-(19) has been solved for the three systems considering two in-depth inspections during 40 years. For the in-depth inspection accuracy $k_{\text {insp }}=1.3$ has been considered for the three systems. The two thresholds governing the probability of occurrence of the essential and preventive maintenance for each component have been selected as $\delta_{E M, i}=0.90 A_{i}(0)$ and $\delta_{P M, i}=0.98 A_{i}(0)$, respectively. These selected thresholds correspond to the previously defined threshold set T2. Nominal costs of 1, 10 and 100 have been considered for inspection, preventive and essential maintenance, respectively.

The defined optimization problem has been solved by means of genetic algorithms (GAs), using the global optimization toolbox provided in MATLAB 2012b. Multi-objective GAs provide Pareto fronts of optimal solutions, representing a set of maintenance schedules constituting dominant solutions with respect to the chosen objectives. MATLAB toolbox utilizes a controlled elitist genetic algorithm, that is a variant of NSGA-II [Deb 2001]. Single point crossover has been used, and the optimization has been performed considering an initial population size of 150 solutions and 200 maximum iterations. The objective function has been implemented to evaluate first the annual failure probability of the system for each branch of the event tree, by using RELSYS software. Average system failure rates are computed by Eqs. (7) and (9). Finally, maximum expected system failure rate and the expected total cost are obtained by Eqs. (13) and (14). In order to increase the computational efficiency, branches with occurrence probability $P\left(B_{k}\right)<10^{-4}$ have been discarded, since they have negligible contribution towards the evaluation of the expected system failure rate. The bookkeeping technique described in Bocchini and Frangopol (2011) has been used to 
further improve the computational efficiency of the routine. Briefly, the objective function has been implemented so that when a new solution is evaluated, it is automatically stored into a table. For each set of design variables, the GA routine checks first if it is possible to retrieve immediately the solution from the table instead of evaluating the objective function itself.

Figure 7(a) depicts the Pareto front obtained for the three systems considering two indepth inspections ( $N_{\text {insp }}=2$ ). As the three Pareto fronts indicate, maximum expected system failure rate varies significantly with respect to the system configuration. Between the three considered systems, the parallel one has the lowest failure probability, and consequently the lowest maximum expected system failure rate. On the contrary, the highest values of the maximum expected system failure rate are associated with the series system. Three particular solutions $X, X^{\prime}$ and $X^{\prime \prime}$ of the Pareto fronts shown in Figure 7(a) are reported in detail in Table 2. These solutions have been chosen so that they have the same expected total cost. The series and series-parallel systems optimal solutions require shorter time intervals between the two in-depth inspections, compared to the parallel system.

For each system configuration, the percentage of increase in total cost $\Delta C$ between the cheapest and the most expensive optimal solutions in the corresponding Pareto front is computed as:

$$
\Delta C=\left|\frac{\min \left(E\left[C_{\text {tot }}\right]\right)-\max \left(E\left[C_{\text {tot }}\right]\right)}{\min \left(E\left[C_{\text {tot }}\right]\right)}\right|
$$

and the corresponding percentage of reduction in the maximum expected annual system failure rate $\Delta h$ as:

$$
\Delta h=\left|\frac{\max \left(h_{\max }\right)-\min \left(h_{\text {max }}\right)}{\max \left(h_{\max }\right)}\right|
$$

where $h_{\max }$ is the maximum expected annual system failure rate. Figure 7(b) presents the values of $\Delta C$ and $\Delta h$ for the three different systems considered in this section. For this particular example, the series system shows the largest $\Delta C$ coupled with the smallest $\Delta h$, 
among the three systems. In contrast, the highest $\Delta h$ is achieved for the series-parallel system. This occurs since the three high-cost optimal solutions involve inspection times in the second half of the system life-cycle, maximizing the probability of performing maintenance on the component with highest deterioration rate (i.e., component 3 in Figure 4(a)). This component has the most critical position in the series-parallel configuration.

\section{Case study: Colorado State Highway Bridge E-17-AH}

As a case study, the proposed method has been applied to the superstructure of the Colorado State Highway Bridge E-17-AH. The bridge reinforced concrete deck is supported by nine steel girders and its cross-section is presented in Figure 8(a). A detailed description of the bridge was given in [Estes 1997]. Considering the superstructure symmetry and that failure of the system is reached by either failure of the deck or any two adjacent girders, the bridge has been studied as the series-parallel model composed by deck and 5 girders shown in Figure 8(b). Neglecting the dead load due to the weight of the structure itself, limit state functions for deck and girders are as follows [Estes 1997]:

$$
\begin{aligned}
& g_{\text {deck }}=\left(0.563 A(t) f_{y}-\frac{A^{2}(t) f_{y}^{2}}{244.8 f_{c}}\right) \gamma_{d}-M_{\text {deck }}(t)=0 \\
& g_{g i r, i}=Z_{i}(t) F_{y} \gamma_{g}-\eta_{i} I M_{g i r, i}(t)=0
\end{aligned}
$$

where $A(t)$ and $f_{y}$ are the cross-sectional area and yield strength of the deck reinforcement bars, respectively; $f_{c}$ is the 28-day compressive strength of deck concrete; $Z_{i}(t)$ is the plastic section modulus of the girder $i ; F_{y}$ is the yield strength of the steel girders; $M_{\text {deck }}(t)$ and $M_{\text {gir, }}(t)$ are, respectively, the moments acting on the deck and girder $i$, due to traffic loads; $\eta_{i}$ and $I$ are the traffic load distribution factor and impact factor of girders, respectively; $\gamma_{d}$ and $\gamma_{g}$ are modeling uncertainty factors of the resistance of deck and girders. 
Load effects and corrosion of deck reinforcement bars and girders have been modeled following the data provided by Estes (1997). For the deck reinforcement bars, a uniform corrosion is assumed. The residual area of the reinforcement bars is:

$$
A(t)=\frac{\pi}{4} n_{b a r} d_{b a r}(t)^{2}
$$

where $n_{b a r}$ is the number of reinforcement bars in the deck and $d_{b a r}(t)$ is the bar diameter at time $t$ which is expressed as

$$
d_{b a r}(t)=d_{0}-0.0203 i_{\text {corr }}\left(t-T_{\text {ini }}\right)
$$

where $d_{0}$ is the initial diameter, $i_{\text {corr }}$ represents the rate of corrosion parameter, and $T_{i n i}$ is the initiation time of corrosion. For the steel girders, the corrosion propagation model proposed by Albrecht and Naeemi (1984) is assumed. Structural loads are evaluated as indicated in Estes (1997). Parameters for the traffic load moment distribution are obtained considering the average daily truck traffic on the bridge and are discussed in details in Estes (1997) and Akgül (2002). The random variables involved in the limit state functions in Eqs. (22) and (23) are reported in Table 3. The series-parallel system of the bridge represented in Figure 8(b) has been analyzed by means of RELSYS software, and the annual failure probability $P_{\text {sys }}(t)$ of the system and its components is plotted in Figure 8(c). As shown, after 50 years of service, the system failure probability is mostly controlled by the reliability of the reinforced concrete deck.

For the determination of the optimum maintenance plan, different possible actions have been considered for deck and girders. Regarding the deck, it has been assumed that the in-depth inspections are able to identify the corrosion penetration in the deck and, therefore, to estimate the residual diameter of the reinforcement bars at the inspection time $d_{b a r}^{(\text {est) }}$. Thus, the estimated residual cross-sectional area of the bars $A^{(e s t)}(t)$ is obtained by Eq. (24). Three possible actions have been considered for the deck: essential or preventive maintenance, and no repair. As stated in the previous section, probability of occurrence of the different repair 
options is dictated by two thresholds, that have been defined in terms of initial mean of the cross-sectional area of the reinforcement bars at the initial time $\mu_{A}(0)$ :

$$
\delta_{E M, \text { deck }}=0.90 \mu_{A}(0) ; \delta_{P M, \text { deck }}=0.98 \mu_{A}(0)
$$

Essential maintenance is performed when the estimated bar cross-sectional area is less then $\delta_{E M, \text { deck }}$, while preventive maintenance is applied if $\delta_{E M, \text { deck }}<A^{(e s t)} \leq \delta_{P M, \text { deck }}$. No repair is considered in the remaining cases. The essential maintenance is assumed to completely restore the initial performance of the deck, while the preventive maintenance keeps the areas of reinforcement bars unchanged (i.e., corrosion is blocked) for the next five years.

In the case of the girders, resistance over time depends on the plastic section modulus $Z_{i}(t)$. Therefore, it has been considered that the in-depth inspection estimates the depth of corrosion in the girder and then, based on Estes (1997), the residual plastic section modulus $Z_{i}^{(e s t)}(t)$. Only the preventive maintenance option has been considered to be performed when the estimated plastic section modulus is less than $98 \%$ of the mean initial one. Otherwise, no repair is performed. Essential maintenance of the girders does not significantly reduce the failure probability of the superstructure, as shown in Figure 8(d) where the annual system failure probabilities of the structure without maintenance, with essential maintenance on the deck, and essential maintenance on the girders at 30 years are compared. Therefore, such an expensive but not so effective option has not been included in the possible maintenance plans. The event tree associated with all possible repair options after one inspection is illustrated in Figure 9.

Cost of essential maintenance on the deck is $\$ 225,600$ corresponding to the cost of deck replacement, based on data provided by Estes (1997). For preventive maintenance on the deck and girders, costs have been assumed as $\$ 40,000$ and $\$ 75,000$, respectively. In-depth inspection cost for the bridge superstructure depends on the accuracy of the inspection itself. High accuracy inspection will, necessarily, be more expensive. Therefore, in-depth cost inspection has been computed as: 


$$
C^{(i n s p)}=\left(C^{*}\right)^{\frac{1}{k_{\text {insp }}}}
$$

where $C^{*}=\$ 50,000$ has been assumed as cost of an ideal inspection (i.e., not subjected to any error), and $k_{\text {insp }} \geq 1$ is the index associated with the inspection accuracy.

The Pareto front of optimal maintenance plans for the bridge has been determined as the solution of the optimization problem described by Eqs. (16) - (19). The minimum interval between two successive in-depth inspections, $\Delta T_{P M}$, is, in this case, 5 years.

$$
t_{\text {insp }}^{(k+1)}-t_{\text {insp }}^{(k)} \geq 5 \text { years } \quad k=1, \ldots, N_{\text {insp }}
$$

GAs and RELSYS have been used for determining the Pareto-optimal solutions for the biobjective optimization problem. Figure 10 shows the Pareto front obtained considering two in-depth inspections ( $N_{\text {insp }}=2$ ), index of inspection accuracy $k_{\text {insp }}=1.3$, and, therefore, using Eq. (27), inspection cost $C^{(i n s p)}=\$ 4,200$. Three representative solutions, $\mathrm{A}, \mathrm{B}$ and $\mathrm{C}$, are selected in Figure 10 and reported in details in Table 4 and Figure 11. The annual system failure rate associated with the three solutions is presented in Figures 11(a), (c), and (e). In particular, the expected system failure rate is compared to the annual system failure rate of the two branches with the highest probability of occurrence. Additionally, the expected cumulative cost profiles of solutions A, B, and C are compared with cumulative cost profiles of the two branches having the highest probability of occurrence in Figures 11(b), (d), and (f).

As shown in Figure 11, optimal solutions with low expected total cost are characterized by early maintenance times. These solutions are selected by the optimizer since the need for essential maintenance in the deck is avoided while attempting to minimize the expected total cost. More specifically, the algorithm selects the inspection times when the options of no repair and preventive maintenance for deck and girders have the highest probability of occurrence (i.e., earlier in service life). Conversely, high expected total cost involves high probability of occurrence of those branches in which essential maintenance for the deck is required at least once. For these cases, the optimal plans involve a first 
inspection/repair around half of the life-cycle of the structure, followed by the second one after a short term (around 10 years).

Finally, to analyze the effect of the inspection accuracy on the optimal maintenance plan, a comparison between two Pareto fronts has been performed, the first one obtained using the previous assumptions (i.e, $k_{\text {insp }}=1.3$ ), and the second one obtained considering perfect inspection (i.e., $k_{\text {insp }}=1.0$ ). The two resulting Pareto fronts, reported in Figure 12(a), show that, when uncertainty in the inspection is taken into account, the expected total cost for a given maximum expected system failure rate is lower than that associated with the perfect inspection case. This is due to the higher cost associated with the perfect inspection. However, reducing the accuracy of the in-depth inspections involves an increasing probability of false alarms. This is shown in Figure 12(b), where a comparison is made between the probabilities of occurrence of the different branches for two solutions ( $\mathrm{A}$ and $\mathrm{A}^{\prime}$ ), selected from the two Pareto fronts and having the same maximum expected system failure rate (see Figure 12(a)). The occurrence probabilities of branches vary significantly when changing the inspection accuracy. For the case with perfect inspection, the scatter in the probability of occurrence of branches is reduced, since it becomes dependent only on the imperfections associated with the prediction model. The probabilities of occurrence of dominant branches (namely 15, 17, 25 and 27), corresponding to the most appropriate management decision, are higher in the case of perfect inspection. Consequently, in this case, the risk of occurrence of false alarms or wrong management decisions is reduced.

\section{Conclusions}

An efficient approach for optimal life-cycle maintenance scheduling for deteriorating systems has been proposed. This approach is based on a bi-objective optimization procedure which simultaneously minimizes the maximum expected annual system failure rate and expected total cost of the inspection and maintenance plans. Effects of imperfections related to structural performance prediction and inspection accuracy have been considered. Different repair options have been taken into account for each component. Predefined thresholds, representative of the deterioration state of the system, were established to evaluate the 
probabilities of occurrence of the different repair options. The optimization problem has been introduced considering three-component systems with different configurations and then applied to an existing bridge considering uncertainties related to material properties, corrosion, traffic loads and inspection outcomes.

On the basis of the presented results, the following conclusions can be drawn:

1. The expected total cost of all inspections and maintenance actions during the lifetime of a structural system is component-dependent, while the expected system failure rate depends on both the system configuration and component failure rate.

2. Different maintenance strategies can be chosen from the Pareto set. Low-cost maintenance plans are mainly associated with no repair or preventive maintenance, providing a small reduction of the expected system failure rate. In these cases, in-depth inspections should be concentrated in the early life of the structure. Maintenance plans with the highest impact on the structural performance are generally associated with in-depth inspections distributed along the last part of the life-cycle of the system. For these strategies, essential maintenance options on critical components are dominant.

3. The presence of constraints related to maximum allowable inspection and maintenance cost and system failure rate are crucial for deciding which strategy should be selected.

4. Improving the inspection accuracy reduces the risk of occurrence of false alarms; therefore, the most appropriate management decisions are more likely to be selected.

Further research on optimization of life-cycle maintenance of deteriorating structures should be performed focusing on (a) inspection accuracy, (b) use of structural health monitoring for information updating, (c) quantifying the effects of repair on structural performance, and (d) assessing service life based on system reliability methods. 


\section{Acknowledgments}

The support by grants from (a) the National Science Foundation (NSF) Award CMS0639428, (b) the Commonwealth of Pennsylvania, Department of Community and Economic Development, through the Pennsylvania Infrastructure Technology Alliance (PITA), (c) the U.S. Federal Highway Administration (FHWA) Cooperative Agreement Award DTFH61-07H-00040, (d) the U.S. Office of Naval Research (ONR) Awards Number N00014-08-1-0188 and Number N00014-12-1-0023 and (e) the National Aeronautics and Space Administration (NASA) Award NNX10AJ20G is gratefully acknowledged. The opinions presented in this paper are those of the authors and do not necessarily reflect the views of the sponsoring organizations

\section{References}

Ang A.H-S., Tang W.H. (1984), "Probability concepts in engineering planning and design. Volume II - Decision, risk and reliability”, J. Wiley and Sons, NY, USA.

Akgül F. (2002), "Lifetime system reliability prediction for multiple structure types in a bridge network”, PhD Thesis, Department of Civil, Environmental, and Architectural Engineering, University of Colorado, Boulder, Colorado.

Albrecht P., Naeemi A. (1984), "Performance of weathering steel in bridges”, NCHRP Report 272, Washington, DC.

Arunraj N.S., Maiti J. (2007), “Risk-based maintenance - Techniques and applications”, Journal of Hazardous Materials, 142, 653-661.

Baek G., Kim K., Kim S. (2009), “Optimal preventive maintenance inspection period on reliability improvement with Bayesian network and hazard function in gantry crane”, Proceedings of the $6^{\text {th }}$ International Symposium on Neural Networks: Advances in Neural Networks - Part III, Wuhan, China 2009, Springer-Verlag, 1190-1196. 
Barone G., Frangopol D.M. (2013), "Hazard-based optimum lifetime inspection/repair planning for deteriorating structures”, Journal of Structural Engineering, 139(12), 04013017, $1-12$.

Bocchini P., Frangopol D.M. (2011), “A probabilistic computational framework for bridge network optimal maintenance scheduling”, Reliability Engineering and System Safety, 96, 332-349.

Caldeira Duarte J.A., Craveiro J.C.T.A., Trigo T.P. (2006), “Opmitization of the preventive maintenance plan of a series components system”, International Journal of Pressure Vessels and Piping, 83, 244-248.

Carino N.J. (1999), "Nondestructive techniques to investigate corrosion status in concrete structures”, Journal of Performance of Constructed Facilities, 13(3), 96-106.

Clark M.R., McCann D.M., Forde M.C. (2003), “Application of infrared thermography to the non-destructive testing of concrete and masonry bridges”, NDT\&E International, 36, 265275.

Deb, K. (2001), "Multi-objective optimization using evolutionary algorithms”, John Wiley and Sons.

Decò A., Frangopol D.M. (2011), "Risk assessment of highway bridges under multiple hazards”, Journal of Risk Research,14(9), 1057-1089.

Estes A.C. (1997), “A system reliability approach to the lifetime optimization of inspection and repair of highway bridges”, PhD Thesis, Department of Civil, Environmental, and Architectural Engineering, University of Colorado, Boulder, Colorado. 
Estes A.C., Frangopol D.M. (1998), “RELSYS: A computer program for structural system reliability analysis”, Structural Engineering Mechanics, 6(8), 901-919.

Estes A.C., Frangopol D.M. (2003), "Updating bridge reliability based on bridge management systems visual inspection results”, Journal of Bridge Engineering, 8(6), 374382.

Frangopol D.M., Liu M., (2007), “Maintenance and management of civil infrastructure based on condition, safety, optimization, and life-cycle cost”, Structure and Infrastructure Engineering, 3(1), 29-41.

Frangopol D.M., (2011), "Life-cycle performance, management, and optimization of structural systems under uncertainty: accomplishments and challenges”, Structure and Infrastructure Engineering, 7(6), 389-413.

Kim S., Frangopol D.M., Soliman M. (2013), “Generalized probabilistic framework for optimum inspection and maintenance planning”, Journal of Structural Engineering, 139(3).

Leemis L.M. (1995), “Reliability, probabilistic models and statistical methods”, NJ, USA, Prentice Hall.

Mori Y., Ellingwood B.R. (1994), “Maintaining reliability of concrete structures. II: optimum inspection/repair”, Journal of Structural Engineering, 120(3), 846-862.

Okasha M.N., Frangopol D.M. (2009), “Time-variant redundancy of structural systems”, Structure and Infrastructure Engineering, 6(1-2), 279-301. 
Okasha M.N., Frangopol D.M. (2010), "Redundancy of structural systems with and without maintenance: an approach based on lifetime functions”, Reliability Engineering and System Safety, 95, 520-533.

Orcesi A.D., Frangopol D.M. (2011a), “A stakeholder probability-based optimization approach for cost-effective bridge management under financial constraints”, Engineering Structures, 33, 1439-1449.

Orcesi A.D., Frangopol D.M. (2011b), "Use of lifetime functions in the optimization of nondestructive inspection strategies for bridges”, Journal of Structural Engineering, 137, 531539.

Ramirez C.M., Liel A.B., Mitrani-Reiser J., Haselton C.B., Spear A.D., Steiner J., Deierlein G. G., Miranda E. (2012), "Expected earthquake damage and repair costs in reinforced concrete frame buildings”, Earthquake Engineering \& Structural Dynamics, 41, 1455-1475.

Wang Z.W., Zhou M., Slabaugh G.G., Zhai J., Fang T. (2011), “Automatic detection of bridge deck condition from ground penetrating radar images”, IEEE transactions on automation science and engineering, 8(3), 633-640. 


\section{Table 1}

Parameters of random variables involved associated with the three-component system performance functions.

\begin{tabular}{llll}
\hline Variables & Component 1 & Component 2 & Component 3 \\
\hline$A_{i}(0)\left(\mathrm{cm}^{2}\right)$ & 3.0 & 2.9 & 3.1 \\
$D R_{i}($ per year $)$ & $2 \times 10^{-3}$ & $0.5 \times 10^{-3}$ & $3 \times 10^{-3}$ \\
$\mu_{f_{y}}(t)(M P a)$ & 250 & 250 & 250 \\
COV of $f_{y}(t)$ & 0.04 & 0.04 & 0.04 \\
$L_{i}(0)(k N)$ & 60 & 60 & 60 \\
COV of $L_{i}(t)$ & 0.05 & 0.05 & 0.05 \\
$l_{i}($ per year $)$ & $0.2 \times 10^{-3}$ & $0.2 \times 10^{-3}$ & $0.2 \times 10^{-3}$ \\
\hline
\end{tabular}

Note: $\mu(t)=$ mean value, and COV = coefficient of variation. 


\section{Table 2}

Optimal solutions for three-component systems in series, series-parallel and parallel configurations considering two in-depth inspections.

\begin{tabular}{cccccc}
\hline Solution & $k_{\text {insp }}$ & $\begin{array}{c}t_{\text {insp }}^{(1)} \\
(\text { years })\end{array}$ & $\begin{array}{c}t_{\text {insp }}^{(2)} \\
(\text { years })\end{array}$ & $\begin{array}{c}\max \left(E\left[h_{\text {sys }}(t)\right]\right) \\
\left(\text { years }^{-1}\right)\end{array}$ & $E\left[C_{\text {tot }}\right]$ \\
\hline $\mathrm{X}$ & 1.3 & 21 & 27 & $5.48 \times 10^{-2}$ & 112 \\
$\mathrm{X}^{\prime}$ & 1.3 & 19 & 28 & $2.15 \times 10^{-2}$ & 112 \\
$\mathrm{X}^{\prime \prime}$ & 1.3 & 10 & 30 & $0.19 \times 10^{-2}$ & 112 \\
\hline
\end{tabular}

Note: Solutions $\mathrm{X}, \mathrm{X}^{\prime}$, and $\mathrm{X}^{\prime \prime}$ are shown in Figure 7. 


\section{Table 3}

Mean $\mu$ and standard deviation $\sigma$ of the random variables associated with the definition of the bridge limit state functions; data from [Estes 1997].

\begin{tabular}{llll|llll}
\hline Variables & Dimensions & $\mu$ & $\sigma$ & Variables & Dimensions & $\mu$ & $\sigma$ \\
\hline$f_{y}$ & $M P a$ & 386 & 42 & $F_{y}$ & $M P a$ & 252 & 29 \\
$f_{c}$ & $M P a$ & 19 & 3.4 & $d_{0}$ & $m m$ & 15.9 & 0.47 \\
$i_{\text {corr }}$ & mm/year & 2.49 & 0.29 & $T_{\text {ini }}$ & years & 19.6 & 7.51 \\
$\eta_{1}$ & - & 0.982 & 0.122 & $\eta_{2}$ & - & 1.14 & 0.142 \\
$\eta_{3}, \eta_{4}, \eta_{5}$ & - & 1.309 & 0.163 & $I$ & - & 1.14 & 0.114 \\
$\gamma_{d}$ & - & 1.0 & 0.1 & $\gamma_{g}$ & - & 1.0 & 0.1 \\
$Z_{i}$ & $m m^{3}$ & Vary over time & $M_{\text {deck }}, M_{\text {gir }, i}$ & $N m$ & Vary over time \\
\hline
\end{tabular}




\section{Table 4}

Optimal solutions for Colorado State Highway Bridge E-17-AH considering two in-depth inspections.

\begin{tabular}{cccccc}
\hline Solution & $k_{\text {insp }}$ & $\begin{array}{c}t_{\text {insp }}^{(1)} \\
(\text { years })\end{array}$ & $\begin{array}{c}t_{\text {insp }}^{(2)} \\
(\text { years })\end{array}$ & $\begin{array}{c}\max \left(E\left[h_{\text {sys }}(t)\right]\right) \\
\left(\text { years }^{-1}\right)\end{array}$ & $\begin{array}{c}E\left[C_{\text {tot }}\right] \\
(\$)\end{array}$ \\
\hline A & 1.3 & 41 & 50 & $0.64 \times 10^{-3}$ & 249,170 \\
B & 1.3 & 24 & 38 & $2.39 \times 10^{-3}$ & 160,010 \\
C & 1.3 & 12 & 21 & $4.92 \times 10^{-3}$ & 77,975 \\
$\mathrm{~A}^{\prime}$ & 1.1 & 40 & 49 & $0.63 \times 10^{-3}$ & 268,770 \\
\hline
\end{tabular}

Note: Solutions A, B, C are shown in Figs.10 and 12(a), and A' in Fig.12(a). 


\section{Figure captions}

Figure 1 Effect of (a) preventive maintenance (PM) and (b) essential maintenance (EM) on structural performance, and (c) probability of different intervention options based on estimated residual capacity.

Figure 2 Event tree associated with a single component subjected to two inspections and considering three different intervention options.

Figure 3 (a) Annual failure rate associated with branches $B_{1}, B_{5}$ and $B_{9}$ in Fig.2 for a single component considering two in-depth inspections at 15 and 25 years, and (b) expected annual failure rate considering different threshold sets.

Figure 4 (a) Series, series-parallel and parallel configurations of a three-component system, and (b) annual failure probability of all components and systems.

Figure 5 Annual system failure rates for three-component systems for the 27 branches associated with a single inspection/repair at 20 years: (a) series, (b) seriesparallel, and (c) parallel system.

Figure 6 Expected annual system failure rates for three-component systems associated with a single in-depth inspection/repair at 20 years considering different threshold sets: (a) series, (b) series-parallel, and (c) parallel system.

Figure 7 (a) Pareto front of optimal solutions for series, series-parallel and parallel systems, considering two in-depth inspections; (b) percentage of increase in total cost and percentage of maximum expected annual system failure rate reduction between the cheapest and the most expensive optimal solutions for each system. 
Figure 8 Colorado State Highway Bridge E-17-AH: (a) superstructure cross-section; (b) series-parallel model; (c) annual failure probability of single components and system; (d) annual system failure probability considering no repair, EM on girders and EM on deck.

Figure 9 Event tree associated with the Colorado State Highway Bridge E-17-AH superstructure considering two in-depth inspections, three different repair options for the deck and two for girders.

Figure 10 Pareto front associated with optimal maintenance plans considering two indepth inspections for the Colorado State Highway Bridge E-17-AH.

Figure 11 Annual system failure rate and cumulative cost profiles for the two branches with highest occurrence probability, compared with corresponding expected values: (a)-(b) optimal solution A, (c)-(d) optimal solution B, and (e)-(f) optimal solution C.

Figure 12 (a) Pareto fronts associated with optimal maintenance plans for the Colorado State Highway Bridge E-17-AH, considering $k_{\text {insp }}=1.0$ and $k_{\text {insp }}=1.3$; (b) branches occurrence probabilities for two solutions of the two Pareto fronts having same maximum expected system failure rate. 
(a)

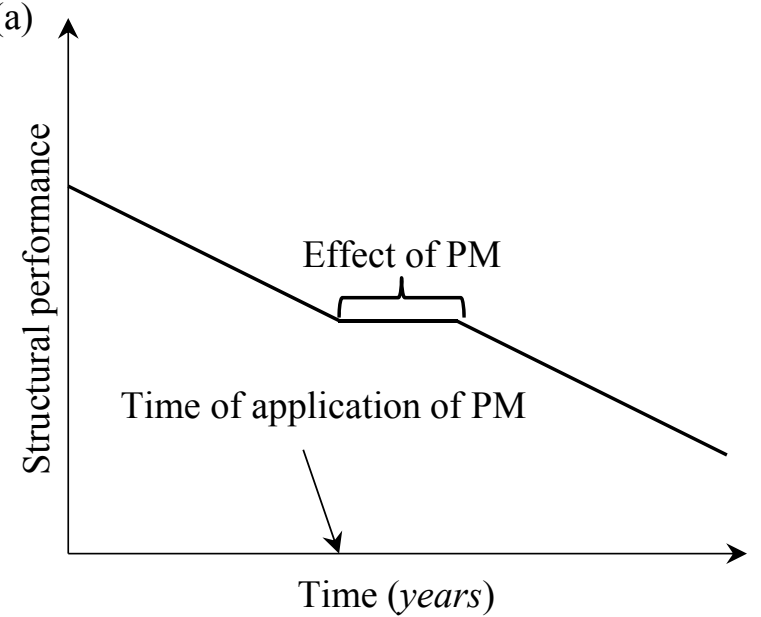

(c)

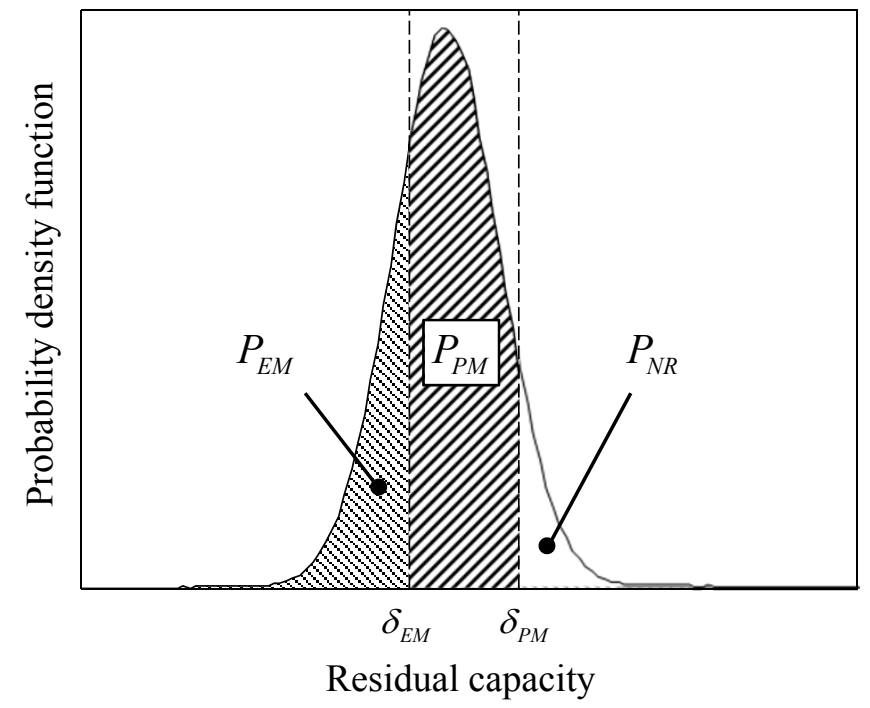

(b)

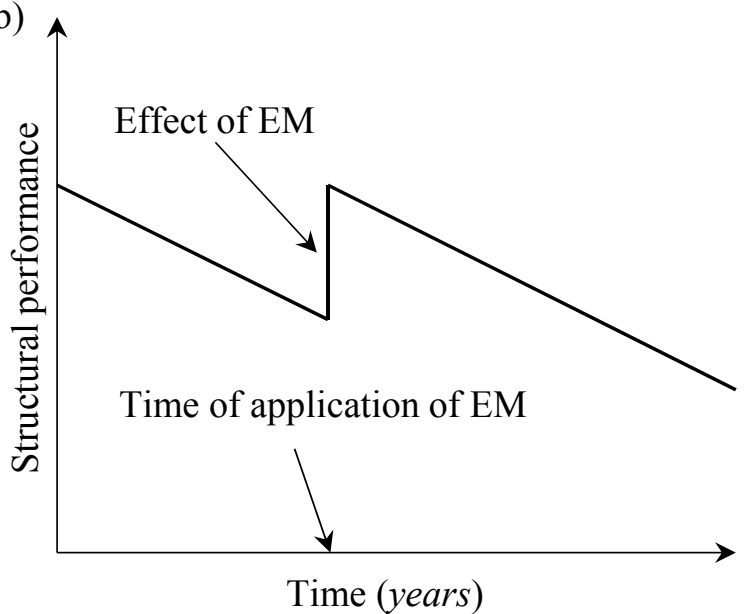




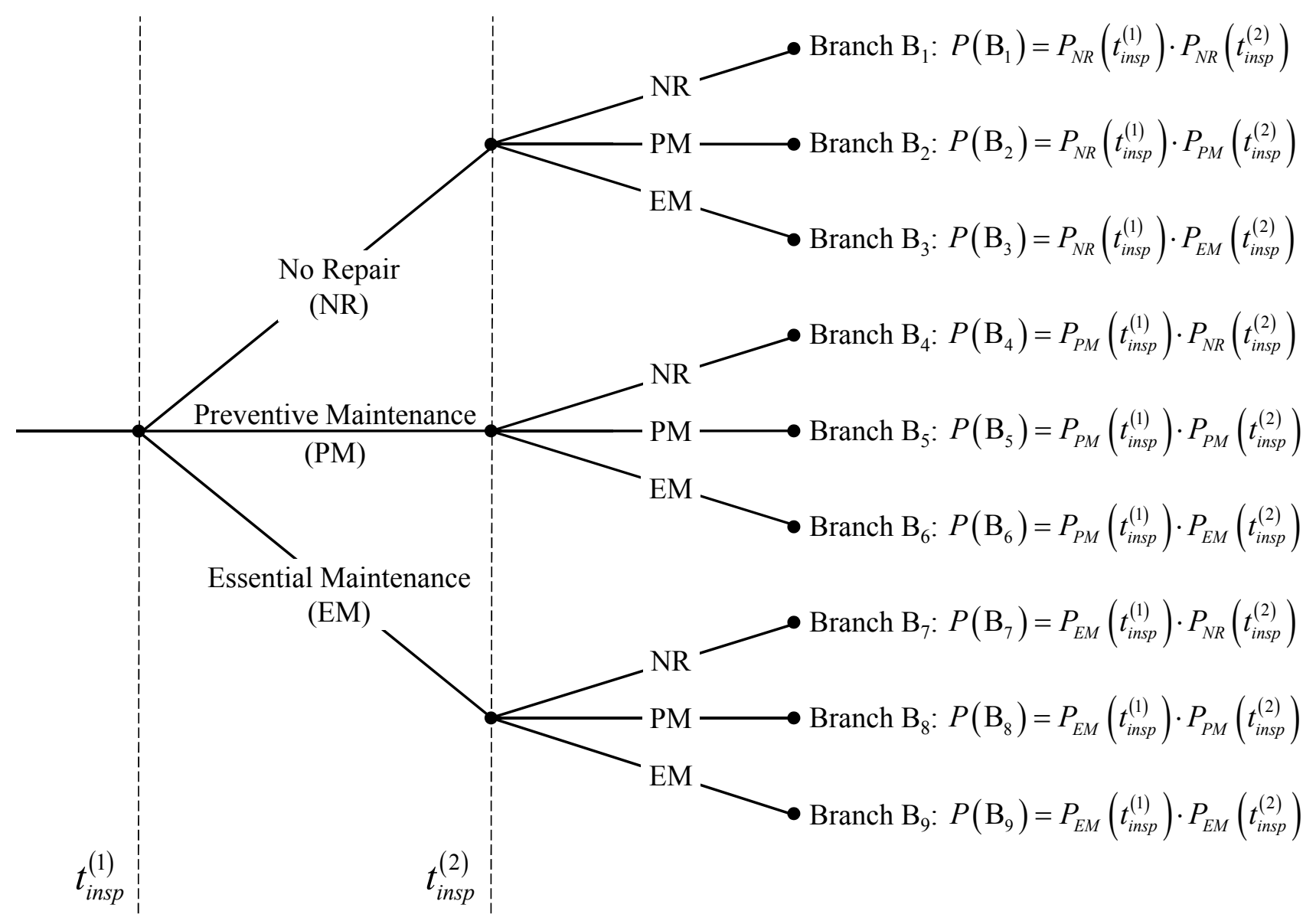


(a)

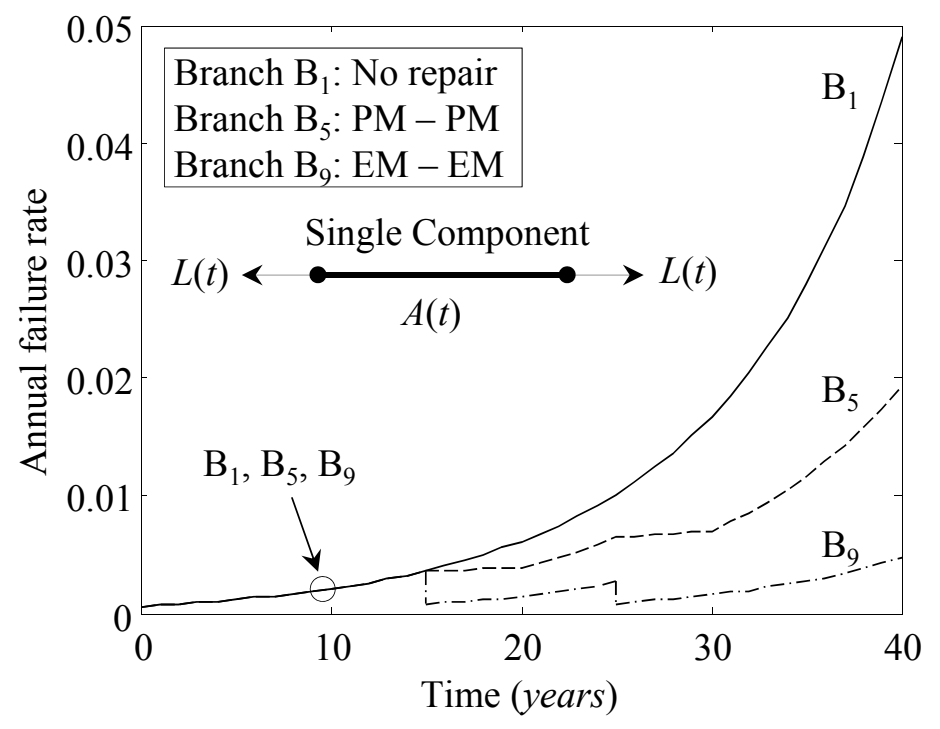

(b)

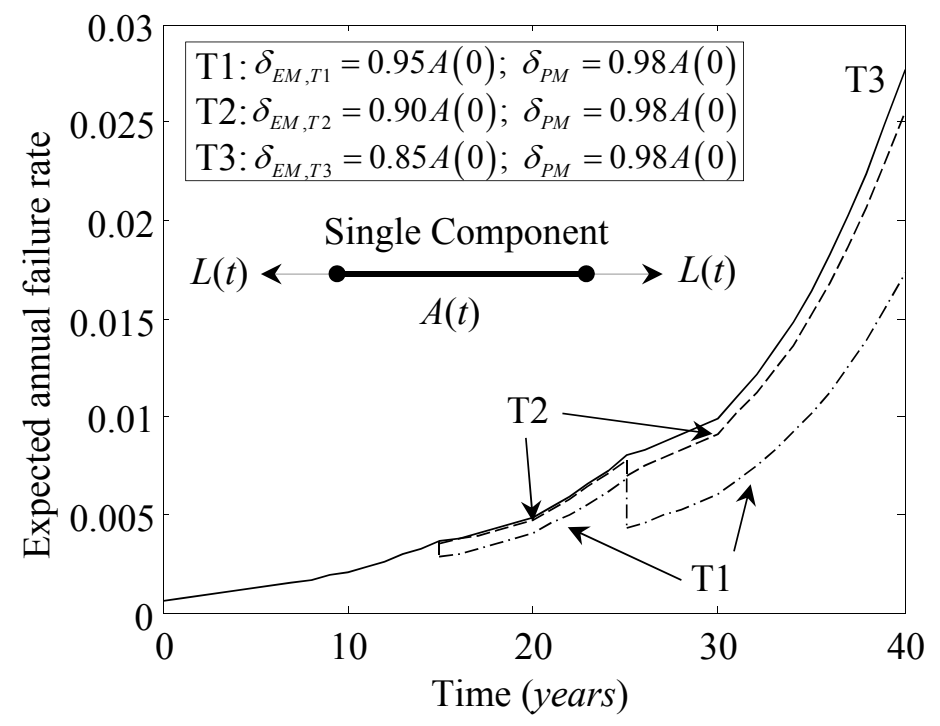


(a)

\section{SERIES SYSTEM}

Component $1 \quad$ Component $2 \quad$ Component 3

\section{SERIES-PARALLEL SYSTEM}

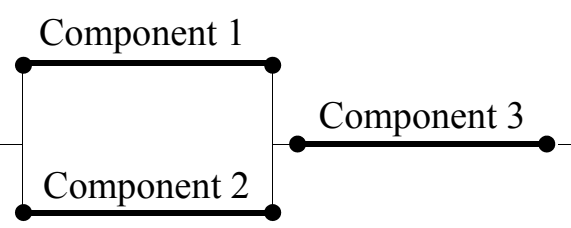

PARALLEL SYSTEM

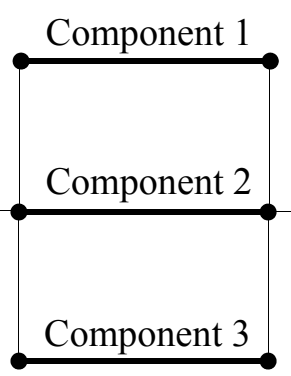

(b)

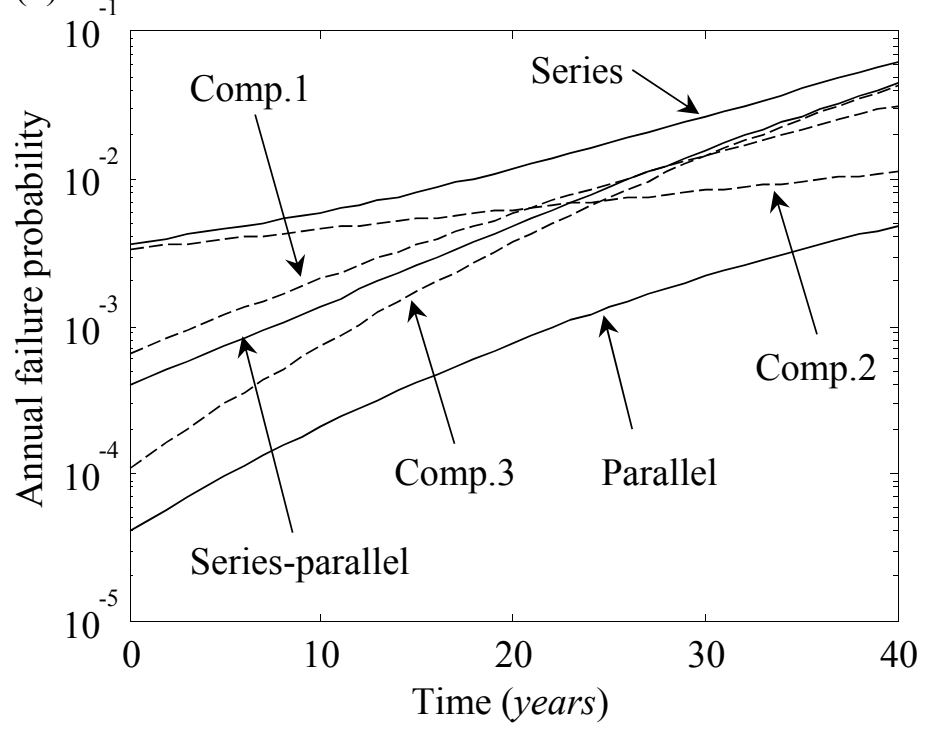


(a)

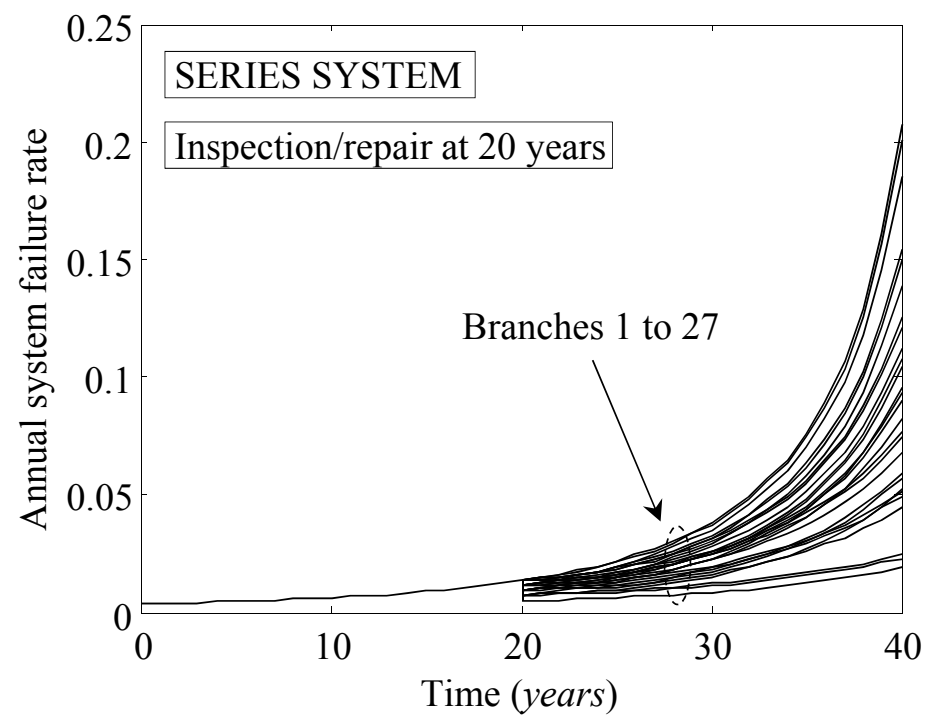

(c)

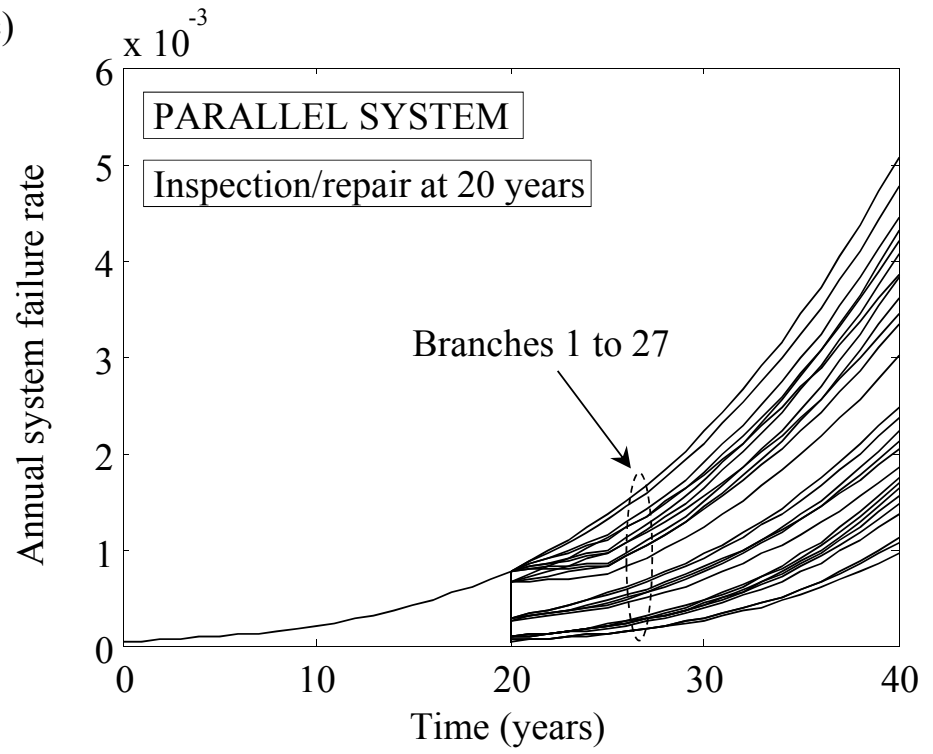

(b)

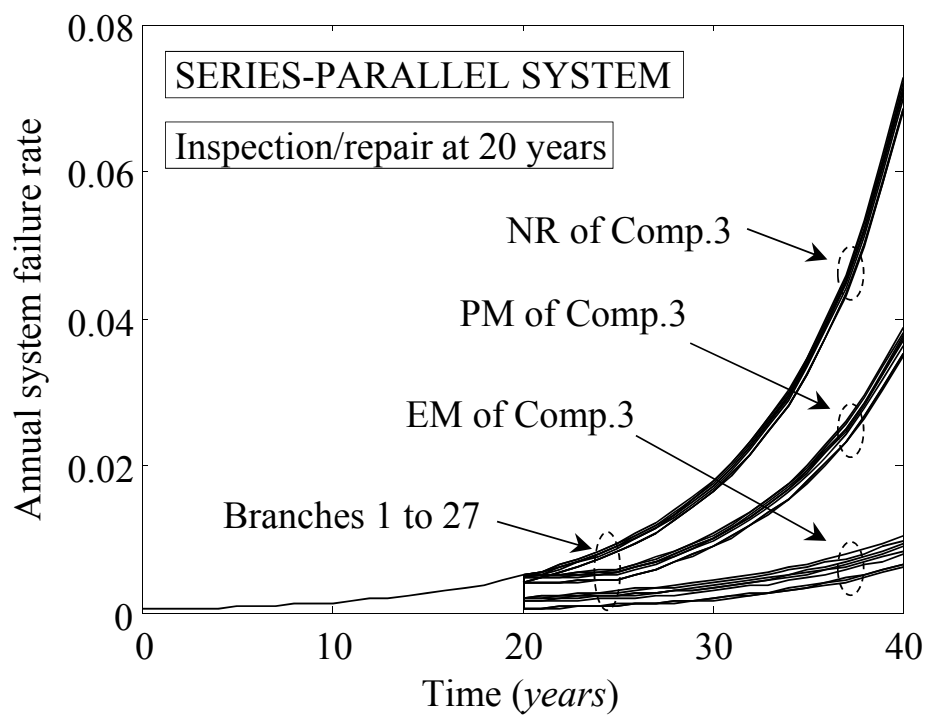


(a)

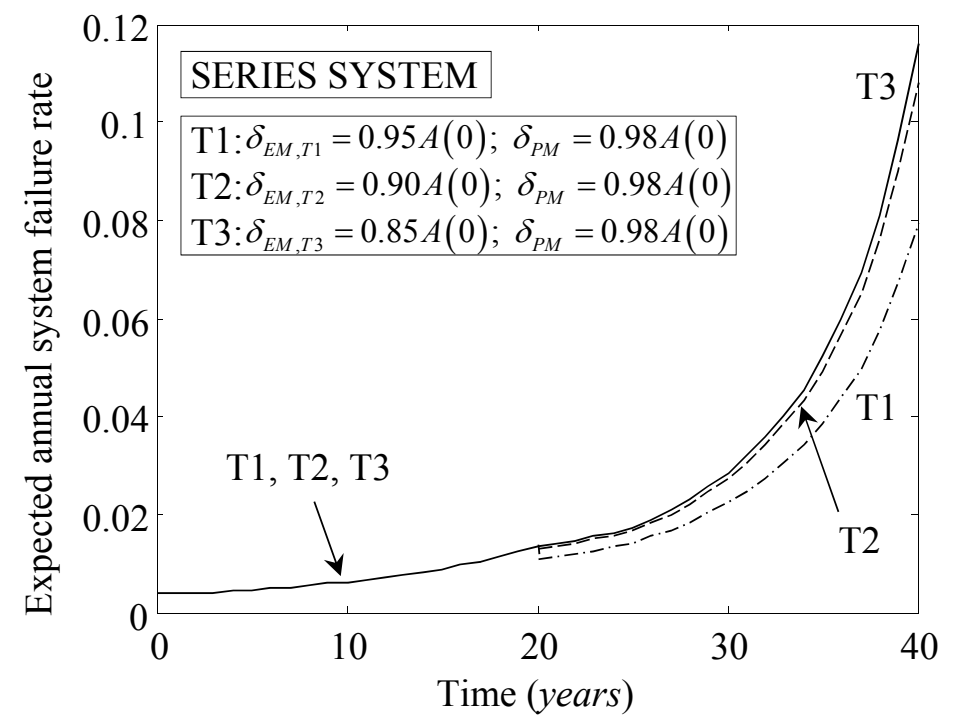

(b)

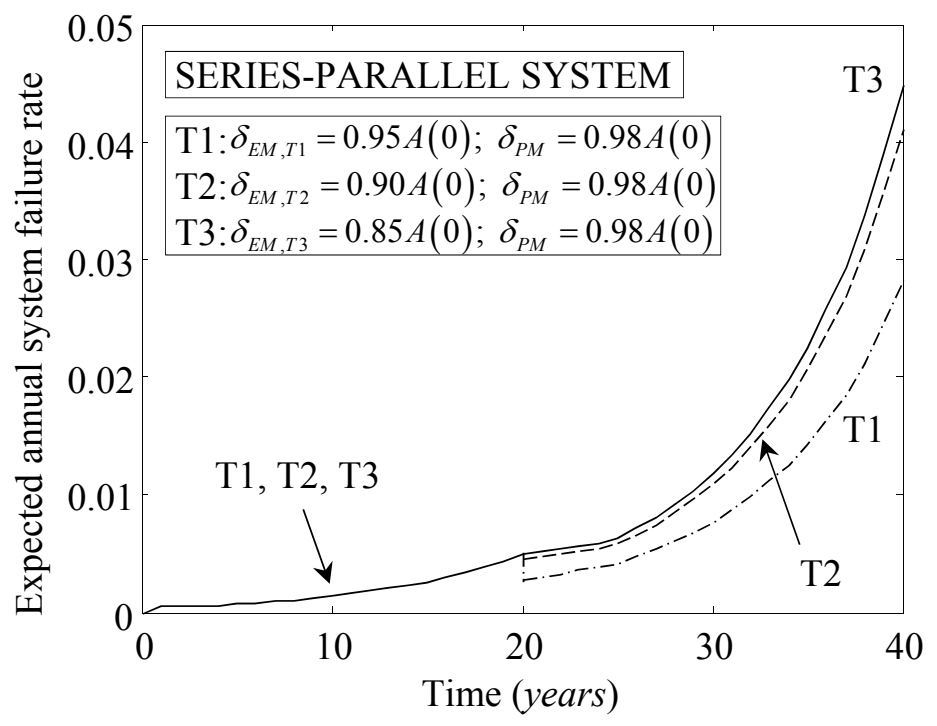

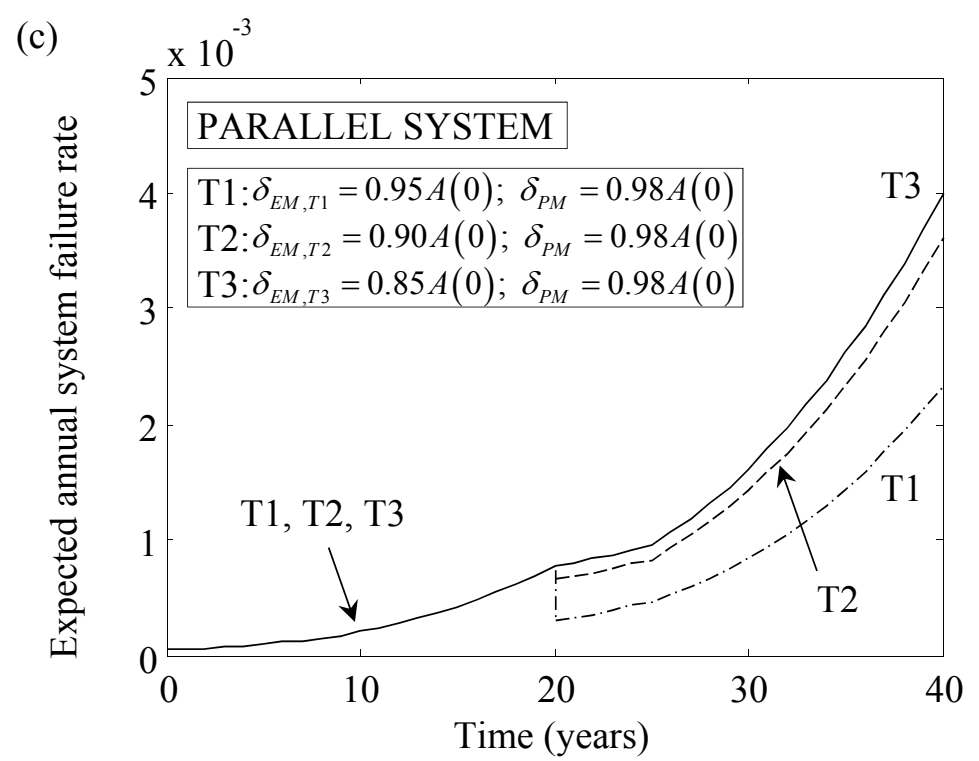

FIGURE 6 
(a)

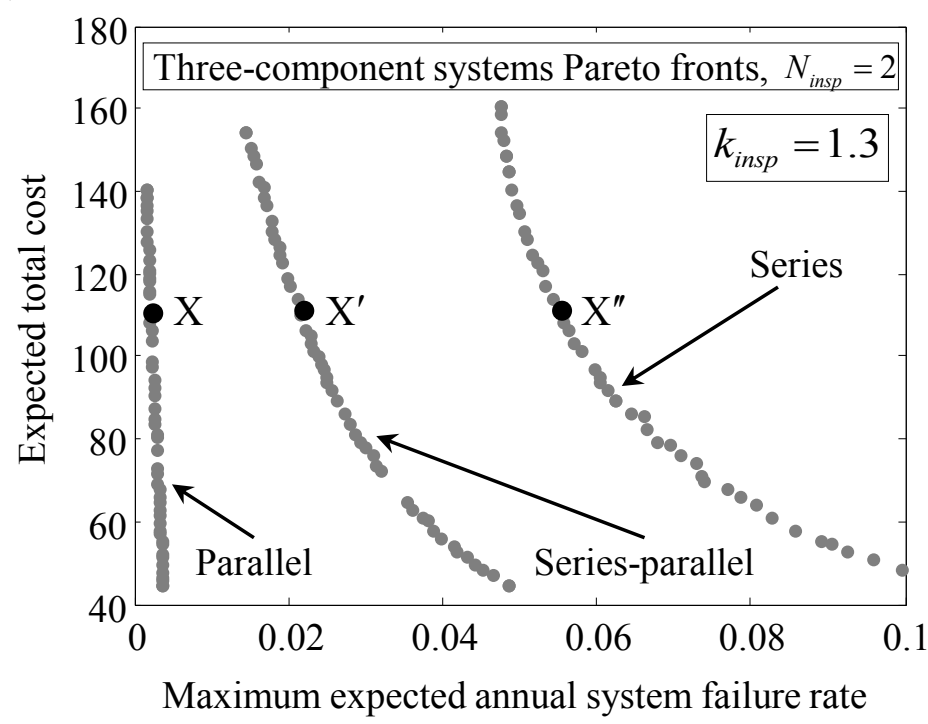

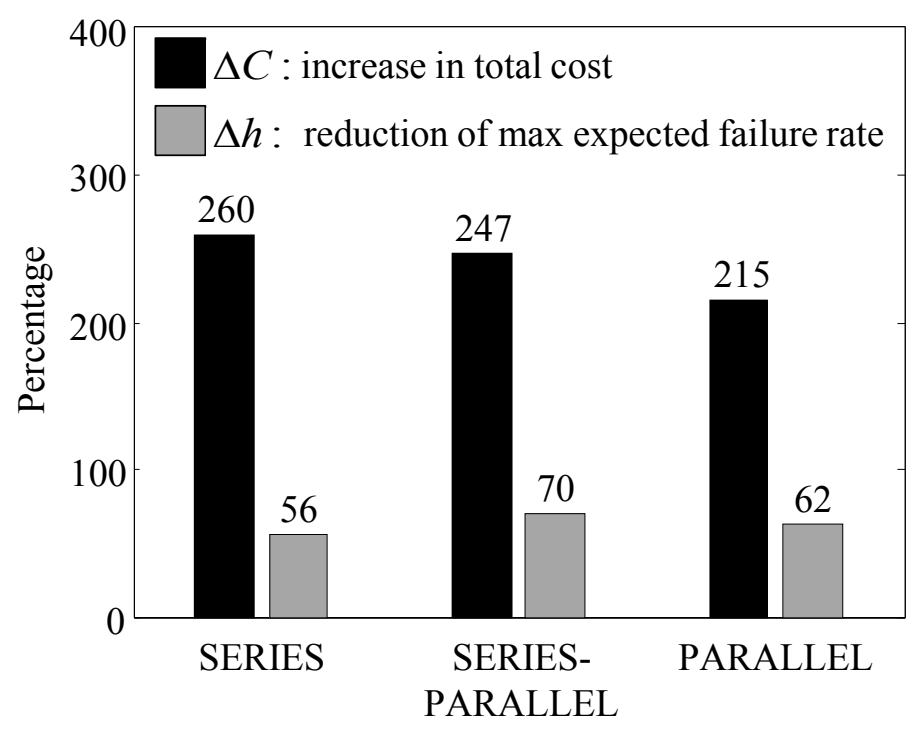


(a)

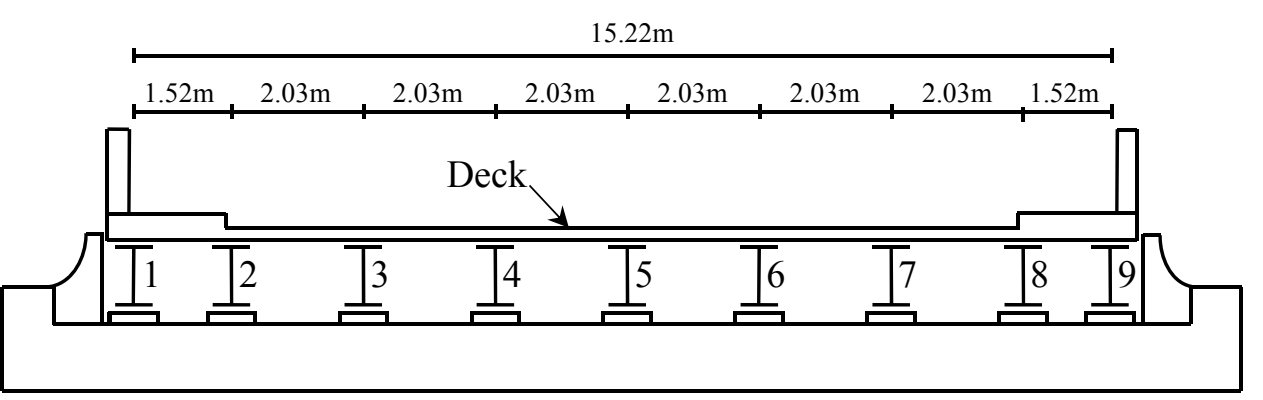

(b)
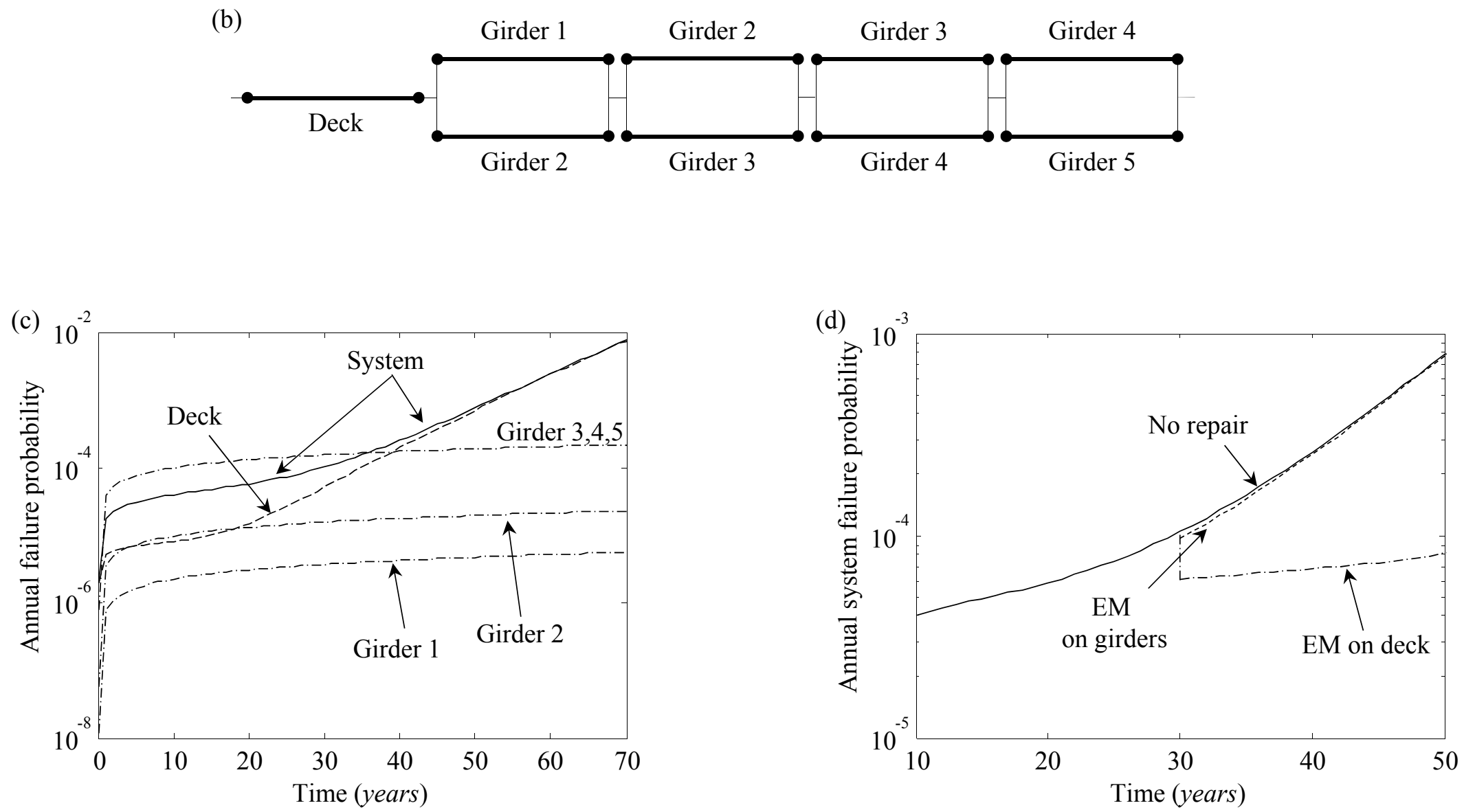

FIGURE 8 


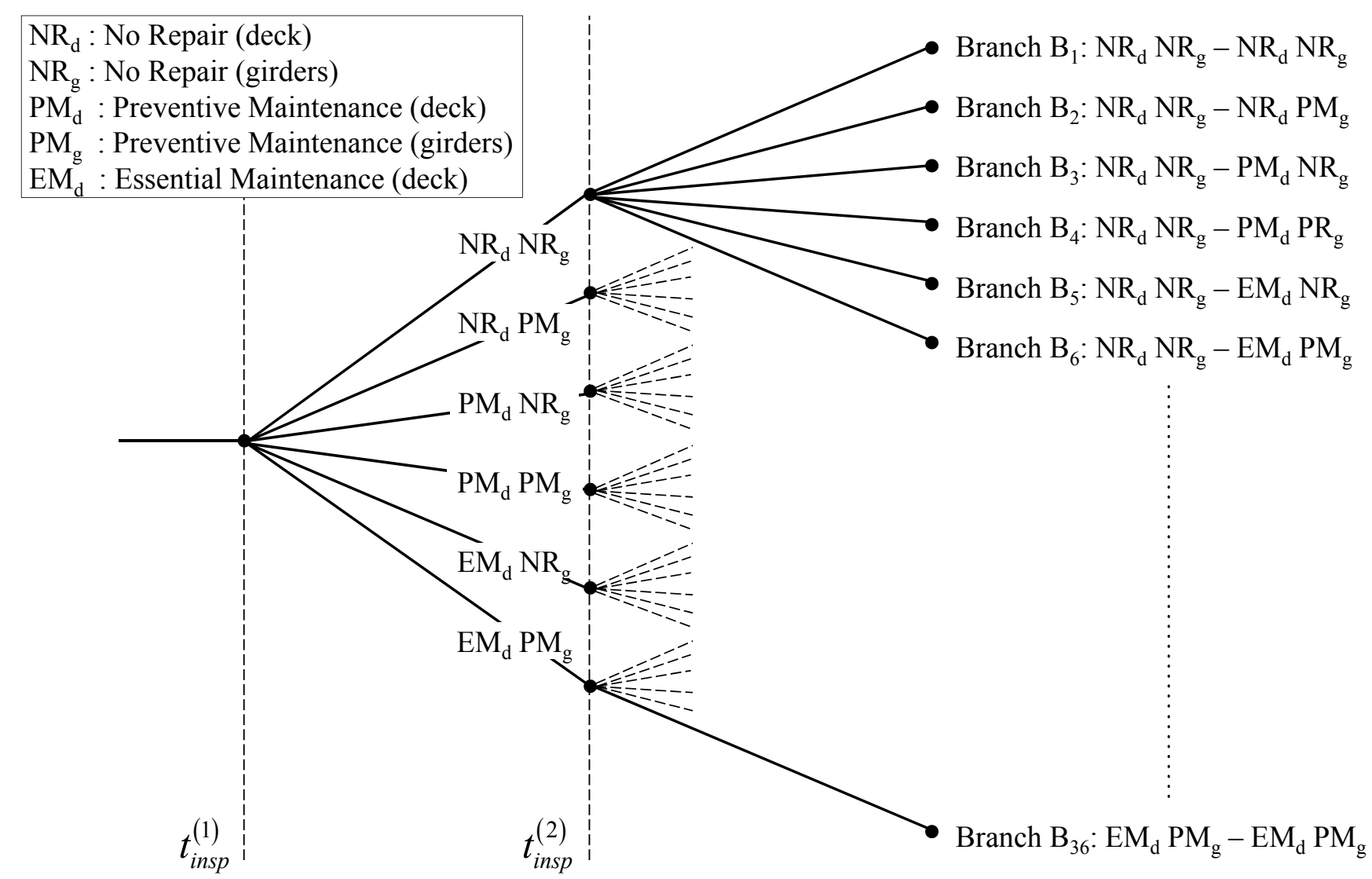




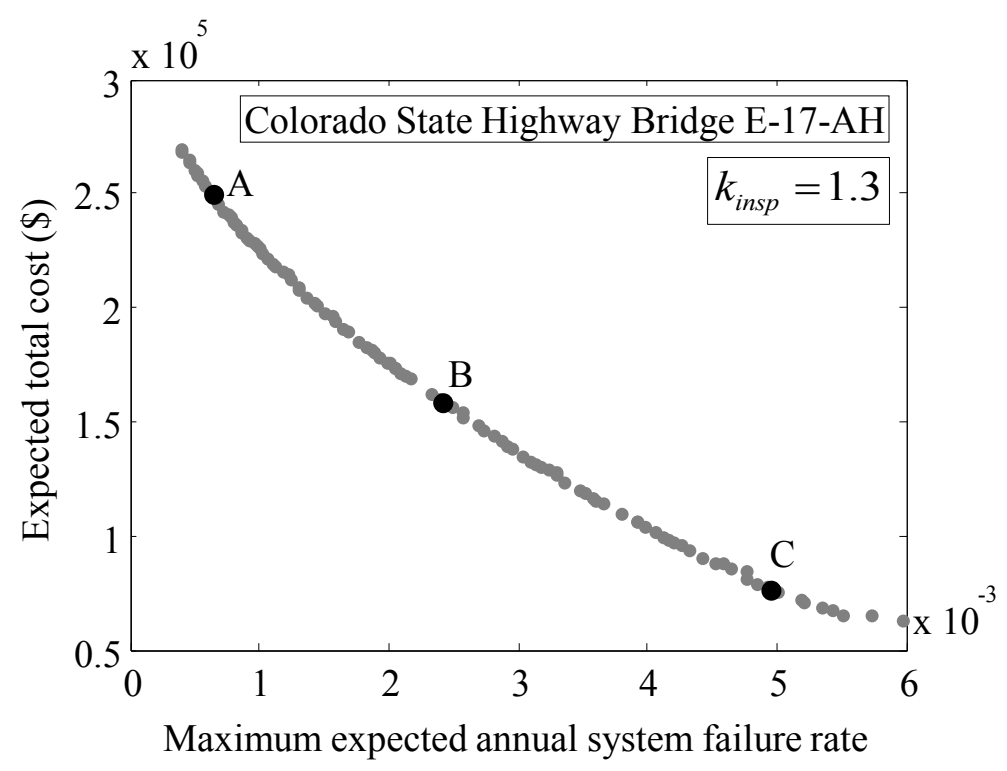


(a)

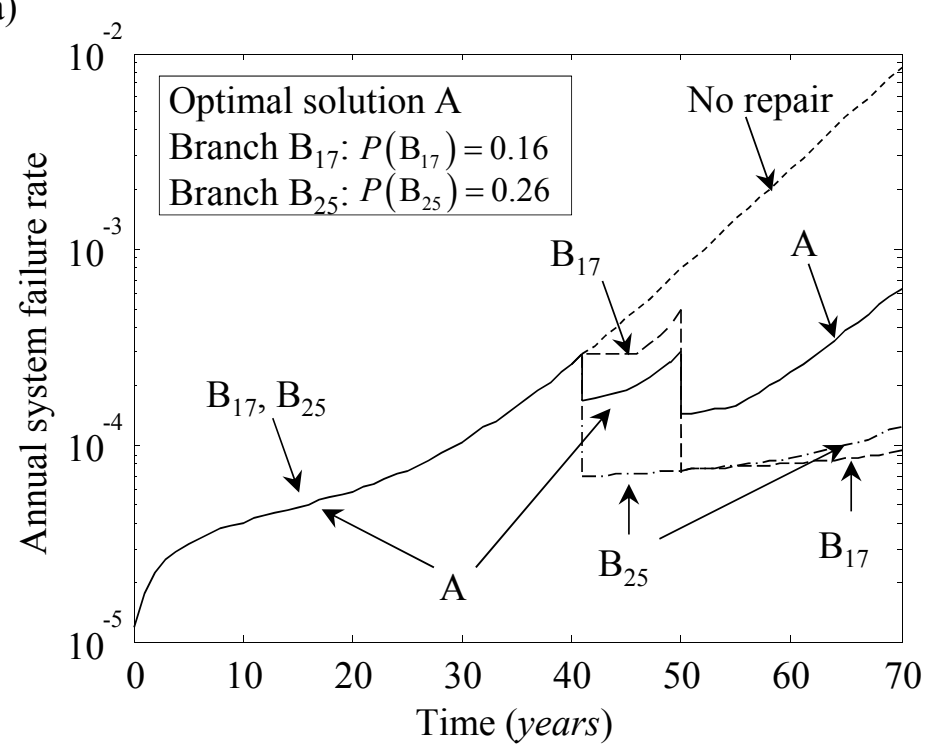

(c)

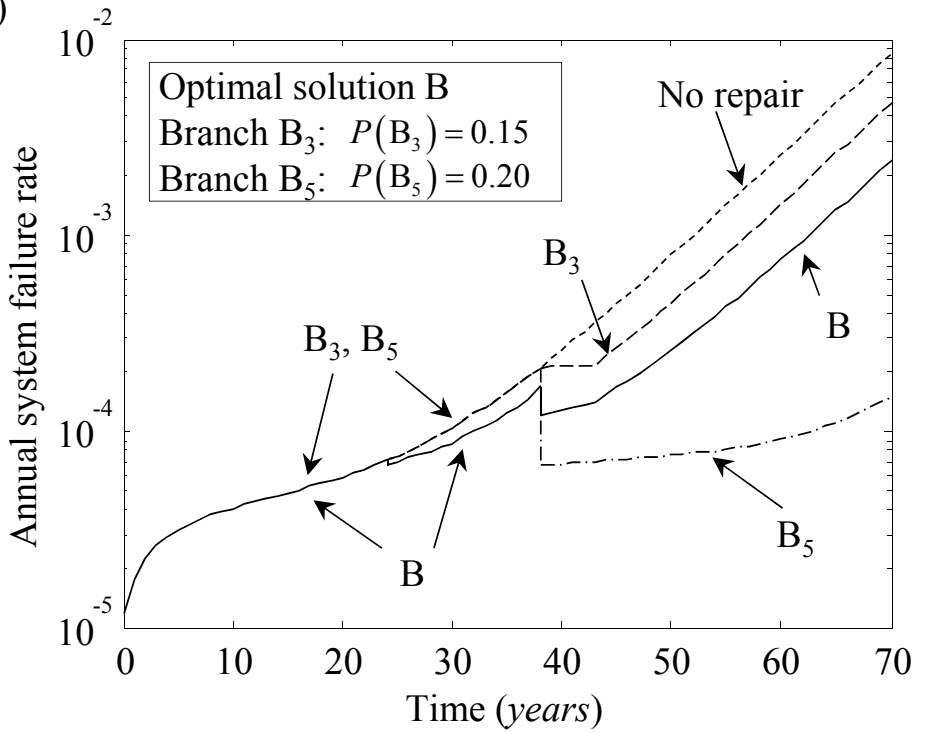

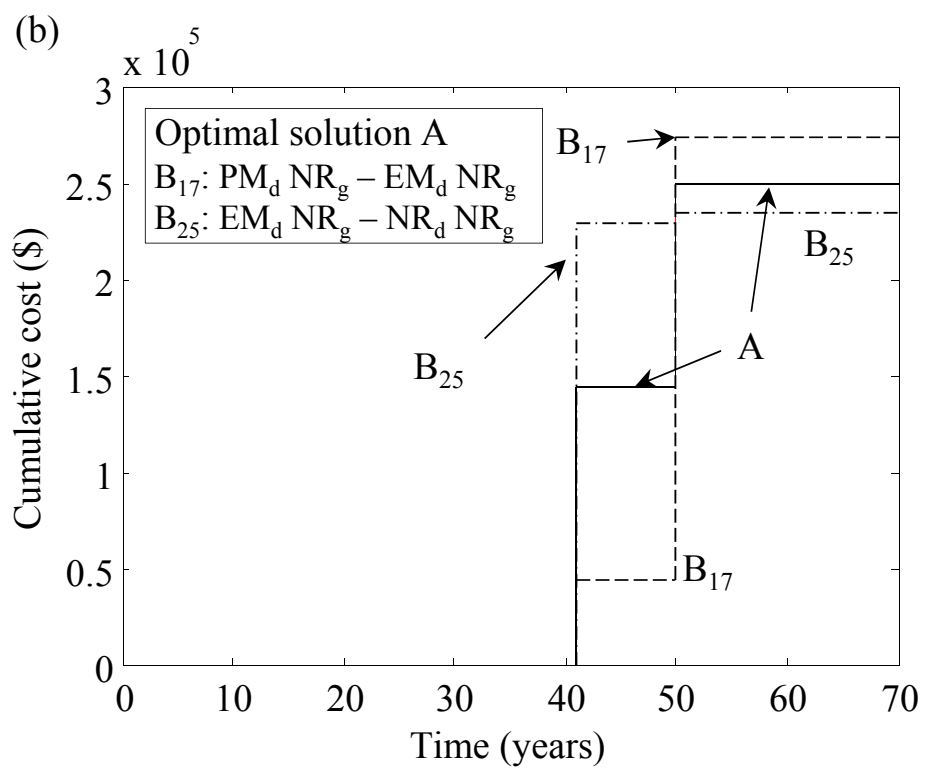

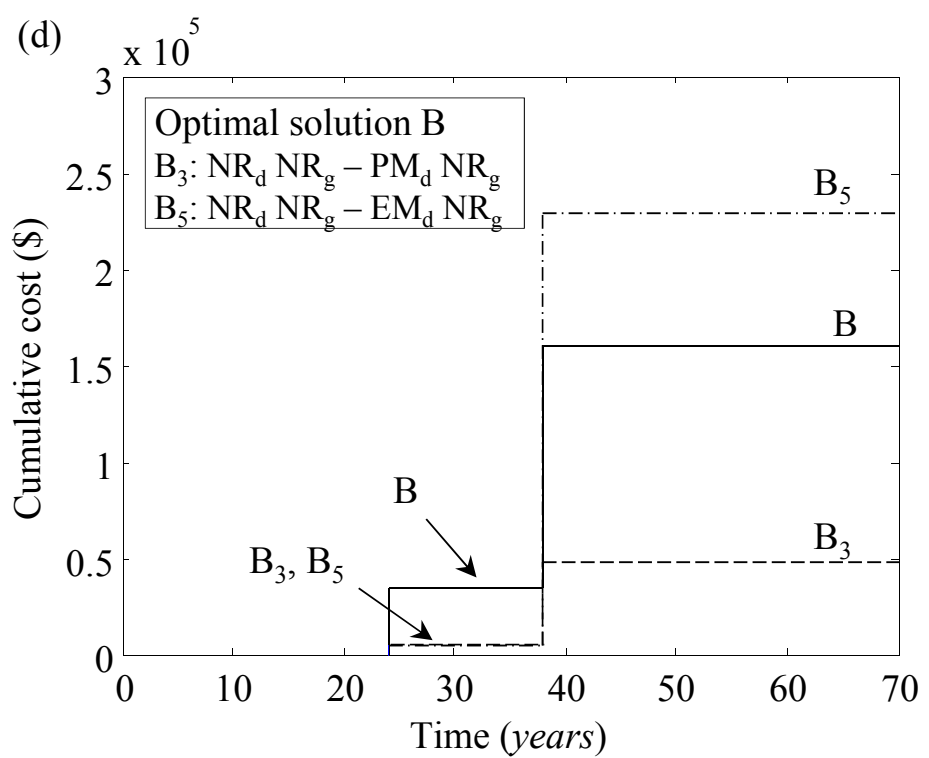


(e)

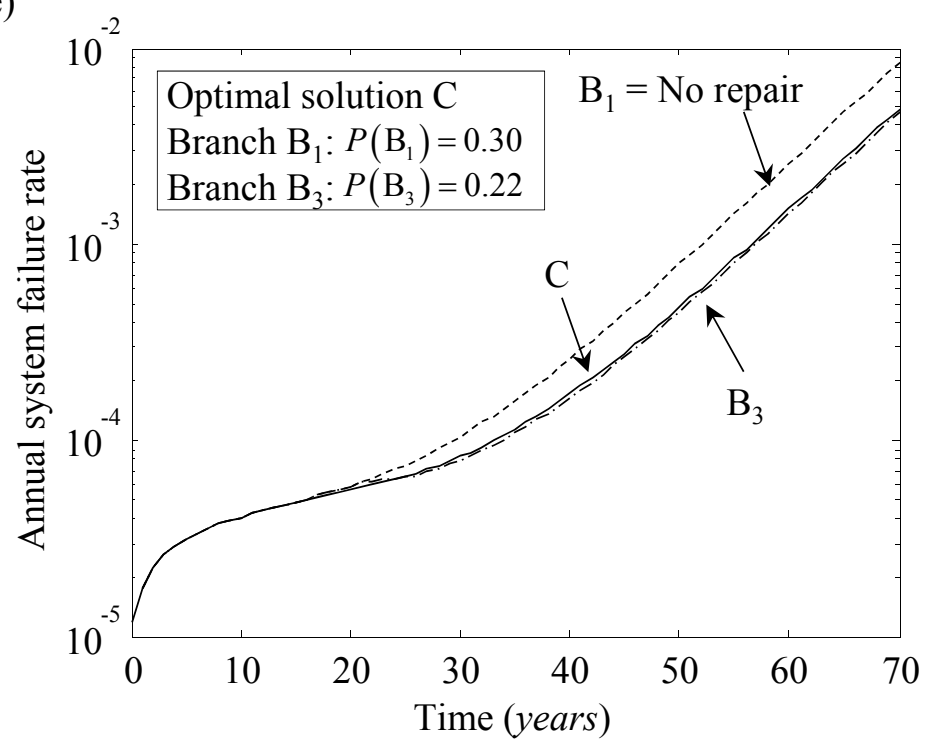

(f)

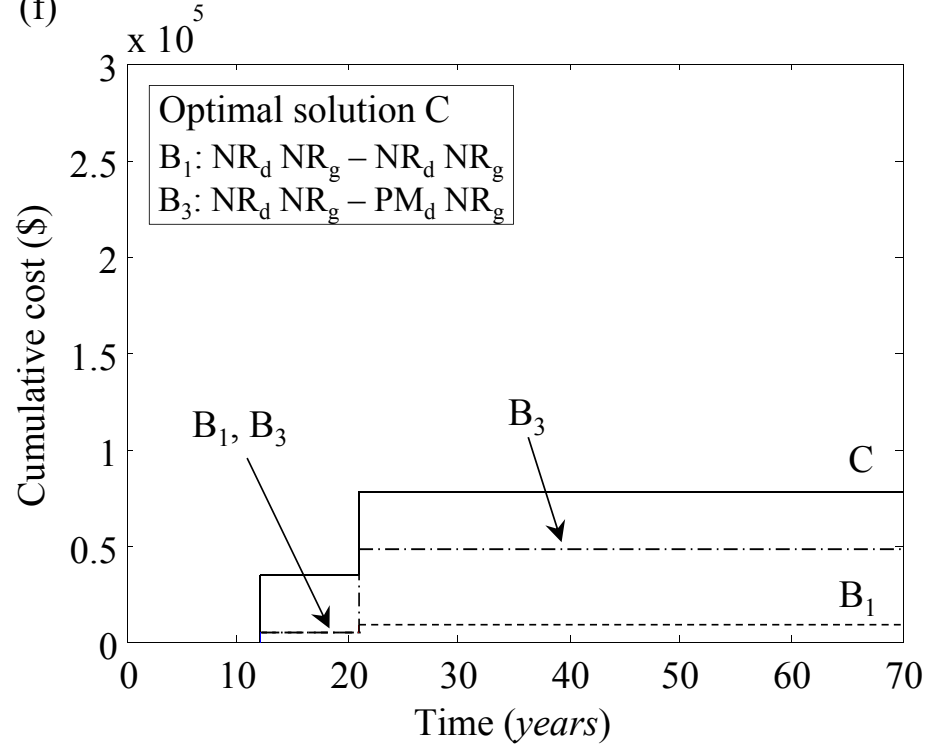


(a)

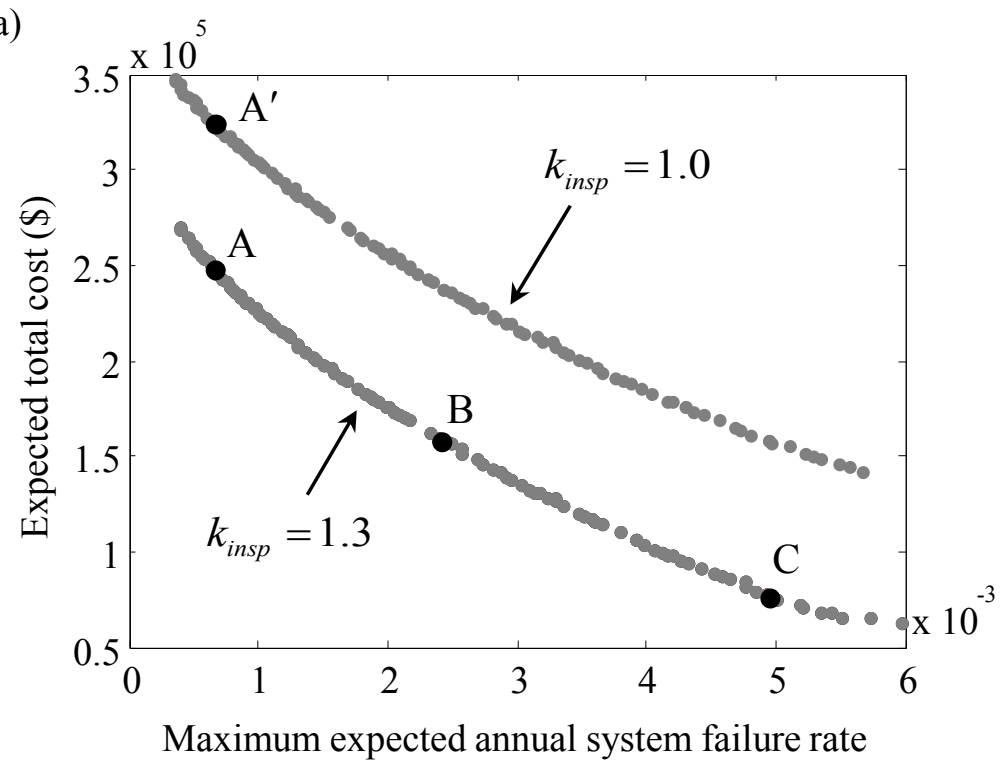

(b) 0.35 Branches occurrence probabilities considering different values of $k_{\text {insp }}$

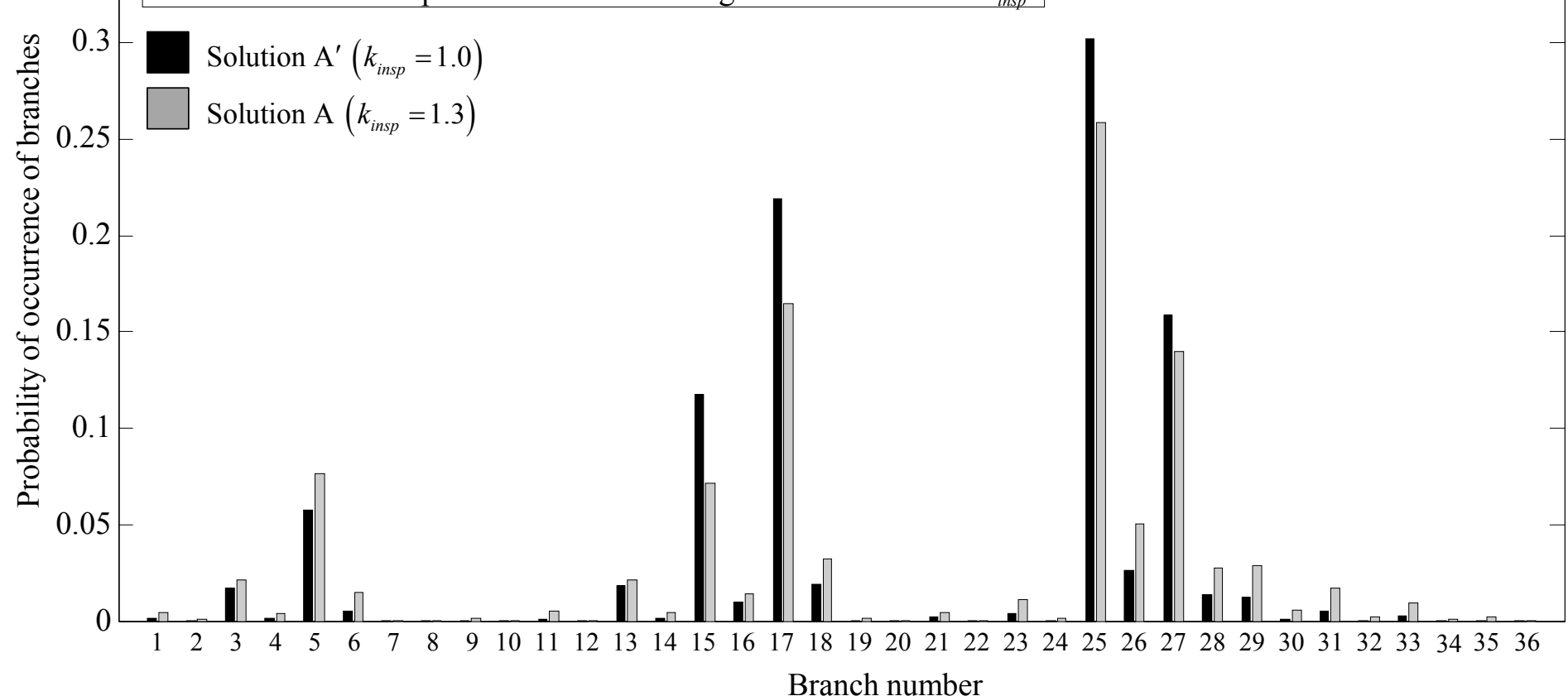

Branch number 